\title{
Synthesis, and Biological Evaluations of Novel Pyrazinoic Acid Derivatives as Anticancer Agents
}

\section{Shiva Akhlaghi}

Ahvaz Jundishapur University of Medical Sciences: Ahvaz Jondishapour University of Medical Sciences

\section{Azar mostoufi}

Ahvaz Jundishapur University of Medical Sciences: Ahvaz Jondishapour University of Medical Sciences

Hadi kalantar

Ahvaz Jundishapur University of Medical Sciences: Ahvaz Jondishapour University of Medical Sciences

Masood Fereidoonnezhad ( $\sim$ masood6289@gmail.com)

Ahvaz Jundishapur University of Medical Sciences https://orcid.org/0000-0003-3405-0228

\section{Research Article}

Keywords: Pyrazinoic acid, cytotoxic activity, apoptotic induction activity, molecular docking

Posted Date: October 1st, 2021

DOl: https://doi.org/10.21203/rs.3.rs-883588/v1

License: (c) (i) This work is licensed under a Creative Commons Attribution 4.0 International License. Read Full License

Version of Record: A version of this preprint was published at Medicinal Chemistry Research on February 19 th, 2022. See the published version at https://doi.org/10.1007/s00044-022-02858-2. 


\section{Abstract}

Pyrazinoic acid or pyrazine-2-carboxylic acid (PA), due to its nitrogenous heteroaromatic ring, can be explored as an anticancer agent. Here, a series of twenty novels PA derivatives have been synthesized and characterized using IR, NMR, and mass spectrums. Their cytotoxic activity was evaluated against three different cancer cell lines, including lung (A549), breast (MCF-7), and colon (HT-29). P16, the most potent compound, showed moderate cytotoxicity with $\mathrm{IC}_{50}$ of $6.11 \mu \mathrm{M}, 10.64 \mu \mathrm{M}$, and $14.92 \mu \mathrm{M}$, against the A549, MCF-7, and HT-29 cell lines, respectively. Furthermore, the effect of this compound against MRC5 as a non-tumoral lung cell line, exhibited a selectivity index of 9.02. The apoptotic induction activity of P16 was also performed on the A549 cell line. The results showed that as the concentration of the compound increases (from 3 to $6 \mu \mathrm{M}$ ), the percentage of induction of apoptosis increases from 8.54\% to $72.4 \%$. Electrophoretic gel mobility shift assays showed that P16 was also able to ROS induce DNA cleavage in the presents of $\mathrm{H}_{2} \mathrm{O}_{2}(1.0 \mathrm{mM})$ in dose-dependent manner. Molecular docking was also applied to anticipate the binding locations and the binding of the synthesized compound with Bcl-2 apoptosis regulator and DNA as their proposed targets.

\section{Introduction}

The raising number of cancer patients throughout the world encourages medicinal chemists to seek novel anticancer agents. The global burden of cancer prevalence and death is steadily rising. In general, an estimated 28.4 million new cases of cancer are predicted in 2040, a 47 percent raise over the corresponding 19.3 million cases in 2020, assuming local rates remain stable in 2020 [1]. DNA contains all genetic information, including cell replication and transcription [2]. Thus, DNA is a significant target for anticancer therapies. Recently, studies have been directed at the interaction of chemicals with this target, causing DNA damage by stopping cancer cells from rapidly dividing. Small heterocyclic molecules interact with DNA through two grooves that run the length of the DNA double helix $[3,4]$. The efficiency of DNA cleavage can be improved using promising coordination compounds, which usually include DNA. The disturbance in the apoptotic pathway has been identified as a characteristic of cancer. [5]. Development of new anticancer agents for apoptosis reactivation methods, which can be used to treat a variety of cancers [6]. Cell shrinkage, and nuclear DNA fragmentation are common biochemical markers of apoptosis [7].

The various nitrogen heterocyclic rings have recently exhibited extraordinarily complicated biological characteristics, making them one of the most influential groups of medical chemistry molecules [8]. Pyrazinoic acid or pyrazine-2carboxylic acid (PA) can be explored as an anticancer agent due to its heterocyclic pyrazine ring. Its derivatives have a wide range of biological activities, such as anti-tuberculosis [9], hepatitis C [10], antidepressant [11], antitumor [12], antifungal-antitumor [13], Antiviral [14].

The structure modification of PA may be utilized to convert its antibacterial to anticancer activity. Since then, derivatives of PA have been recognized as an alteration of DNA methylation and apoptosis. Recently, PA was used to treat colorectal cancer (CRC). Treatment with PA ameliorated the metabolic changes caused by CRC, indicating that it has an acceptable anti-proliferative effect [15]. Bortezomib is a combination of PA, phenylalanine, and boronic acid that has been approved by the FDA for the treatment of multiple myeloma. One of the most important pathways of bortezomib associated with antitumor efficacy is a proteasome inhibitor that could improve signal transduction and apoptosis [16]. 
In this study, we designed and synthesized novel PA derivatives utilizing the Passerini multicomponent reaction. The compounds were identified by Fourier transform infrared spectroscopy (FTIR) and Nuclear Magnetic Resonance $\left({ }^{1} \mathrm{H}\right.$ $\left.\mathrm{NMR},{ }^{13} \mathrm{C}-\mathrm{NMR}\right)$, and Mass spectrometry (MS), as well as physical properties determination such as appearance, and melting point. Furthermore, their cytotoxicity was evaluated against three cancer cell lines, A549 (lung cancer), MCF7 (breast cancer), and HT29 (colon cancer), as well as non-tumorigenic lung cell line (MCR5). To experimentally evaluate the DNA-binding activity of the compound, the electrophoretic mobility shift assay was performed. The effects of the most cytotoxic compounds (P5 and P16) on the induction of apoptosis in the A549 cell line were also investigated. Using molecular docking, the binding energy of the synthesized compounds, as well as their types of interactions had been studied with Bcl-2 apoptosis regulator and DNA as their proposed targets.

\section{Results And Discussion \\ 2.1. Chemistry}

The general synthetic strategy employed to synthesized the PA derivatives was based on the passerine multicomponent reaction [17] under normal state, using isocyanide, different aldehyde derivatives, and PA (Scheme 1). To purify the product, the recrystallization process, using a combination of methanol and water, or plate chromatography using 230-400 mesh silica gel, and a solution of $50 \%$ ethyl acetate and $50 \% n$-hexane, was applied. The obtained compounds were characterized using (IR, ${ }^{1} \mathrm{HNMR},{ }^{13} \mathrm{CNMR}$, and Mass) spectrums. The existence of a chloro pattern (1:2) was also convincingly demonstrated by mass spectrometry (MS).

\subsection{Anticancer activity}

\subsubsection{In vitro cytotoxic activity}

In this study, novel PA derivatives were designed, synthesized and their cytotoxic activity against three human cancer cell lines such asA549 (lung), MCF7 (breast), and HT-29 (colon) was evaluated. To demonstrate their selectivity among normal and cancerous cell lines, the cytotoxicity of these compounds was also assessed against a normal lung cell line (MRC5). Almost all of the synthesized compounds had shown higher anti-proliferative activity than PA. Of twenty synthesized compounds, P16 has shown promising anticancer activity with IC 50 of $6.11 \mu \mathrm{M}$, $10.64 \mu \mathrm{M}$, and $14.92 \mu \mathrm{M}$ against the A549, MCF-7, and HT-29 cell lines, respectively. Also, P5 showed moderate cytotoxicity with $\mathrm{IC}_{50}$ of $14.09 \mu \mathrm{M}, 8.90 \mu \mathrm{M}$, and $16.38 \mu \mathrm{M}$, against A549, MCF7-7, and HT-29 cell lines, respectively. P5 exhibited higher cytotoxicity than P16 against the MCF-7 cell line (Table 1). 
Table 1

In vitro cytotoxic activity of the synthesized compounds against three cancerous cell lines: A549, MCF-7, and HT-29, as well as a normal lung cell line (MRC5).

\begin{tabular}{|c|c|c|c|c|c|}
\hline \multirow[t]{2}{*}{ Name } & \multicolumn{4}{|c|}{$\mathrm{IC}_{50}(\mu \mathrm{M} \pm \mathrm{SD})$} & \multirow[t]{2}{*}{ Selectivity-Index ${ }^{1}$} \\
\hline & A549 & MCF-7 & HT-29 & MRC5 & \\
\hline P1 & $44.19 \pm 0.01$ & $61.82 \pm 1.54$ & $55.41 \pm 1.11$ & $98.76 \pm 1.53$ & 2.23 \\
\hline P2 & $61.62 \pm 0.76$ & $68.86 \pm 0.78$ & $49.19 \pm 0.03$ & $100.36 \pm 0.64$ & 1.62 \\
\hline P3 & $97.11 \pm 0.19$ & $53.71 \pm 1.38$ & $35.34 \pm 0.82$ & $>100$ & - \\
\hline P4 & $47.10 \pm 0.69$ & $47.54 \pm 0.03$ & $13.51 \pm 0.31$ & $>100$ & - \\
\hline P5 & $14.09 \pm 0.66$ & $8.90 \pm 0.84$ & $16.38 \pm 0.74$ & $81.90 \pm 2.18$ & 5.18 \\
\hline P6 & $43.57 \pm 1.20$ & $22.18 \pm 1.03$ & $26.53 \pm 1.04$ & $93.54 \pm 0.06$ & 2.14 \\
\hline P7 & $>100$ & $>100$ & - & $>100$ & - \\
\hline P8 & $>100$ & $>100$ & - & $>100$ & - \\
\hline P9 & $>100$ & $>100$ & - & $>100$ & - \\
\hline P10 & $98.69 \pm 1.18$ & $92.97 \pm 0.19$ & - & $>100$ & - \\
\hline P11 & $>100$ & $>100$ & - & $>100$ & - \\
\hline P12 & $>100$ & $97.27 \pm 0.38$ & - & $>100$ & - \\
\hline P13 & $97.02 \pm 0.17$ & $67.50 \pm 0.41$ & - & $>100$ & - \\
\hline P14 & $78.15 \pm 0.82$ & $39.82 \pm 0.32$ & $39.65 \pm 0.09$ & $>100$ & - \\
\hline P15 & $86.24 \pm 0.59$ & $36.14 \pm 0.62$ & $22.20 \pm 0.93$ & $>100$ & - \\
\hline P16 & $6.11 \pm 0.05$ & $10.64 \pm 0.84$ & $14.92 \pm 0.09$ & $55.14 \pm 1.11$ & 9.02 \\
\hline P17 & $40.09 \pm 0.66$ & $31.70 \pm 0.02$ & $17.47 \pm 2.8$ & $94.28 \pm 1.35$ & 2.35 \\
\hline P18 & $>100$ & $>100$ & - & $>100$ & - \\
\hline P19 & $>100$ & $>100$ & - & $>100$ & - \\
\hline P20 & $71.21 \pm 1.88$ & $38.84 \pm 0.22$ & $35.64 \pm 0.43$ & $>100$ & - \\
\hline $\mathrm{PA}^{2}$ & $>100$ & $>100$ & $>100$ & - & - \\
\hline Cisplatin & $9.37 \pm 1.43$ & $15.72 \pm 1.38$ & $89.48 \pm 3.65$ & $14.67 \pm 1.38$ & 1.56 \\
\hline \multicolumn{6}{|c|}{${ }^{1} \mathrm{IC}_{50}$ for MRC-5 cell line/IC $\mathrm{C}_{50}$ for A549 cell line } \\
\hline
\end{tabular}

Cisplatin, one of the most efficient anticancer drugs, was chosen as a reference drug in this study. As shown in Table 2, cisplatin $\mathrm{IC}_{50}$ is $9.37 \mu \mathrm{M}, 15.72 \mu \mathrm{M}$, and $89.48 \mu \mathrm{M}$ against the A549, MCF-7, and HT-29 lines, respectively. One-way ANOVA statistical analysis showed that the differences between the $\mathrm{IC}_{50}$ of cisplatin, and P16 are statistically significant in all the studied cell lines. Thus, P16 showed higher anti-proliferative activity than cisplatin 
in all the studied cell lines. On the other hand, P5 was also shown higher cytotoxicity in comparison to cisplatin in MCF-7, and HT-29 cell lines.

MRC5, a normal epithelial lung cell line, is utilized to evaluate the toxicity of the synthesized compounds on normal cells and determine the selectivity index between cancerous and normal cells. All the synthesized compounds, particularly P1, P2, P5, P6, P16, and P17 with a selectivity index of 2.23, 1.62, 5.18, 2.14, 9.02, and 2.35, respectively, demonstrated higher selectivity for human lung cancer cells while causing less harm to normal epithelial lung cells. Obviously, this series of compounds showed a better selectivity index and therapeutic window than cisplatin.

\subsubsection{Structure-activity relationship}

The activity of the synthesized PA derivatives illustrates that substituted by both electron-withdrawing groups like ( $\mathrm{F}$, $\mathrm{Cl}, \mathrm{Br}$, and $\left.\mathrm{NO}_{2}\right)$ and electron-donating groups like $\left(\mathrm{OCH}_{3}, \mathrm{Me}\right)$ in the B-ring of the structure have a promising impact on the cytotoxic activity against all the studied cancer cell lines. For example, P16, which has a chloro group in the B ring, has higher cytotoxic activity on the A549, MCF-7, and HT-29 cell lines than the other halo groups. However, the movement of the chloro group in ring $B$ from para to meta, and ortho reduced the inhibitory effect on the studied cancer cell lines. The presence of one $\mathrm{Cl}$ group on the $\mathrm{B}$ ring showed good to moderate cytotoxic activity $\left(\mathrm{IC}_{50}<40 \mathrm{M}\right.$ in MCF-7 and HT-29 cell lines). Besides, by inserting the chloro group in positions 2 and 4, such as P17, a suitable compound in terms of in vitro cytotoxicity activity is produced, although weaker than P16. In all the studied cancer cell lines, substituting withdrawing groups like halogens in the B-ring in the order of $\mathrm{Cl}>\mathrm{Br}>\mathrm{F}$, can affect the antitumor activity of compounds. $\mathrm{P} 10$, with $\mathrm{NO}_{2}$ group in 2, and 4 positions, showed weak anticancer activity. Also, the placement of other electron-withdrawing groups such as nitro did not show effective activity on the studied cancer cell lines. On the other hand, when an electron donor groups such as methoxy $\left(\mathrm{OCH}_{3}\right)$, is embedded in the $B$ ring as illustrated in the (P1-P6) compounds, it shows significant cytotoxic activity against studied cancer cell lines. As evident in $\mathrm{P} 5$, which encompasses $\mathrm{OCH}_{3}$ in 2 and 5 positions, the highest antitumor activity is observed in the MCF-7 cell line. The $\mathbf{P} 4$ with the $\mathrm{OCH}_{3}$ group in 3 and 4 positions in the $\mathrm{B}$ ring has the most potent anticancer activity against the HT-29 cell line.

\subsection{3. apoptosis assay using flow cytometry}

Here, we applied the AnnexinV/PI kit to evaluate the effect of P5, and P16, as the most potent antitumor compounds, on the apoptosis induction against A549 cell lines. As shown in Fig. 1, with the rise in the concentration of P5 from 7.0 to $14.0 \mu \mathrm{M}$, the percentage of cells in the apoptotic process increases significantly from 0.6 percent in untreated cells to $4.27 \%$, and $42.7 \%$ in treated cells. On the other hand, p16 at concentrations of $3 \mu \mathrm{M}$, and $6 \mu \mathrm{M}$ was used to induce apoptosis and the percentage of apoptotic cells is significantly increased from $8.28 \%$ at $3 \mu \mathrm{M}$ to $72.4 \%$ at $6 \mu \mathrm{M}$. Although both compounds cause apoptotic cell death, P16 is more potent than P5. These findings showed that, P16, and P5 could induce programmed cell death in a concentration-dependent manner in A549. Hence, parts of their cytotoxic effects go through apoptosis induction.

\subsubsection{Gel electrophoresis study}

Gel electrophoresis has been carried out to monitor the cleavage of DNA by selective synthesized compounds. The experiment followed a technique that had already been reported in the literature [18]. It's well defined that there has been large accumulation of $\mathrm{H}_{2} \mathrm{O}_{2}$ in several tumor tissues [19] and it was reported earlier that some complexes like $\mathrm{Cu}$, and Pt containing compounds [20] induced DNA cleavage activity in the presence of reducing agents like $\mathrm{H}_{2} \mathrm{O}_{2}$, we also explored the possible nuclease activity of P5, and P16 in the presence of $\mathrm{H}_{2} \mathrm{O}_{2}$. 
As shown in Fig. 2A, B, P5 was failed to induce DNA cleavage independently. It was unable to ROS induce DNA cleavage in the presents of $\mathrm{H}_{2} \mathrm{O}_{2}(1.0 \mathrm{mM})$ and it was unable to displace with safe stain in DNA supercoil. On the other hand, Fig. 2C, D shows that, P16 was unable to induce DNA cleavage independently. However, it was able to ROS induce DNA cleavage in the presents of $\mathrm{H}_{2} \mathrm{O}_{2}(1.0 \mathrm{mM})$ in dose dependent manner (Fig. 2D). It should be noted that P16 was unable to displace with safe stain in DNA supercoil.

\subsubsection{Molecular docking studies}

Recently, pyrazine derivatives have been studied due to their heteroaromatic nature in medicinal chemistry. The interaction of pyrazine was evaluated using different targets. The results revealed that the nitrogen atoms of pyrazine have the prominent roles in the binding primarily through acceptor hydrogen bonding [21]. In this study, all the synthesized compounds were docked conducted to molecular docking studies to understand their interactions and acquire further information on their molecular binding mechanism with Bcl-2 apoptosis regulator (PDB ID: 6QGK) and DNA (PDB ID: 1LEX).

The interactions of the synthesized PA derivatives with Bcl-2 were explored, and it was found that the most significant amino acids in binding pyrazine to Bcl-2 were Phe104, Ala149, Met115, and Phe112 (Fig. 3). The main interaction site of pyrazine was through arene- $\mathrm{H}$, donor hydrogen bonding, and hydrophobic interactions with Phe104, Met115, and Ala149, respectively. For example, P10 interacts with Bcl-2 through three different interactions, including hydrophobic interactions, donor hydrogen bonding, and $\pi$-Stacking. As seen in Fig. 3A, the pyrazine ring in P10 via hydrophobic interaction bind to the Leu137 and Ala149, as well as binds to Phe104 through $\pi$-Stacking. There exists a hydrogen bonding between the nitrogen of amid group and Asp111. A hydrophobic interaction between the cyclohexane ring and Met115 is also observed. There is a hydrogen bonding between the nitrogen of amid group and Asp111, and a hydrophobic interaction between cyclohexane and Met115. According to Fig. 3A, $\pi-$ Stacking binding has also existed between pyrazine with Phe112, and benzene with Phe104. The hydrophobic interactions between cyclohexane and Phe153, Ala149, and Val133 were also observed.

According to Fig. 3B, P16 has shown hydrophobic interactions between its cyclohexane ring and Phe153, Ala149, and Val133. There are also existed two stacking binding between pyrazine with Phe112, and benzene with Phe104.

Furthermore, the molecular binding of the synthesized compounds with DNA was also studied. Thymine and cytosine base was found to have the highest interaction in binding with PA derivatives. Both P10, and P16 compounds are located in the minor groove of DNA. There exists a hydrogen bonding between the carbonyl of amide group and T8. Also, pyrazine has a donor hydrogen bonding with the C9 base and the nitro group has a hydrophobic interaction with C6 (Fig. 3C). The main interaction of P16 with DNA was also explored (Fig. 3D). It interacts through the nitrogen on the pyrazine ring with the T7 base via a donor hydrogen bonding and a carbonyl ester group via an acceptor hydrogen bonding with the same thymine base (T7). Also, this group has a hydrophobic interaction with another T8 base. There is also a donor hydrogen bonding between the nitrogen of amide group and the $\mathrm{C} 9$ base (Fig. 3D).

Apart from experimental tests, the validation of the docking protocol was also explored using RMSD. According to Fig. 4, the RMSD of the co-crystal ligand has been reported as $0.95 \AA$, and $0.79 \AA$ with $\mathrm{Bcl}-2$ apoptosis regulator, and DNA, respectively. The $\Delta$ Gbind values for $\mathrm{Bcl}-2$, ranged from -7.59 to- $6.02 \mathrm{kcal} / \mathrm{mol}$, whereas the $\Delta \mathrm{Gbind}$ values for DNA ranged from -9.65 to $4.43 \mathrm{kcal} / \mathrm{mol}$ (Table 2 ). 
The docking binding energies of all the synthesized compounds on $\mathrm{Bcl}-2$, and DNA receptors as well as some ADME descriptors, especially drug-likeness rules (Lipinski's rule), which were calculated by DruLiTo are shown in Table 2. The Lipinsky rule of five (RO5) descriptors such as Molecular Weight (MW), logP, AlogP, H-bond Acceptor (HBA), Hbond Donor (HBD), Total Polar Surface Area (TPSA), Active Metabolic Rate (AMR), and the number of Rotatable Bonds (nRB), intrinsic solubility (log S), and gastrointestinal absorption (GA) were calculated for all the synthesized compounds. All compounds pass the drug-likeness filter, which is based on Lipinski's rule of five (Table 2).

Table 2

The docking binding energies as well as some ADME descriptors of all the synthesized compounds.

\begin{tabular}{|c|c|c|c|c|c|c|c|c|c|c|c|c|}
\hline \multirow[t]{2}{*}{ Name } & \multicolumn{2}{|c|}{$\begin{array}{l}\text { Molecular } \\
\text { docking } \\
\text { (kcal/mol) }\end{array}$} & \multirow[t]{2}{*}{ MW } & \multirow[t]{2}{*}{$\log P$} & \multirow[t]{2}{*}{ Alogp } & \multirow[t]{2}{*}{ HBA } & \multirow[t]{2}{*}{ HBD } & \multirow[t]{2}{*}{ TPSA } & \multirow[t]{2}{*}{ AMR } & \multirow[t]{2}{*}{$\mathrm{nRB}$} & \multirow[t]{2}{*}{$\log S$} & \multirow[t]{2}{*}{ GA } \\
\hline & $\begin{array}{l}\text { BCL- } \\
2\end{array}$ & DNA & & & & & & & & & & \\
\hline P1 & -6.99 & -9.25 & 345.99 & 0.73 & -2.928 & 7 & 0 & 77.32 & 94.4 & 8 & -3.69 & High \\
\hline P2 & -6.98 & -9.01 & 345.99 & 0.52 & -2.928 & 7 & 0 & 77.32 & 77.32 & 8 & -3.69 & High \\
\hline P3 & -6.74 & -8.90 & 345.99 & 0.52 & -2.928 & 7 & 0 & 77.32 & 77.32 & 8 & -3.69 & High \\
\hline P4 & -6.83 & -8.71 & 373.98 & 0.76 & -3.427 & 8 & 0 & 86.55 & 86.55 & 9 & -3.77 & High \\
\hline P5 & -6.68 & -9.16 & 373.98 & 0.76 & -3.427 & 8 & 0 & 86.55 & 86.55 & 9 & -3.77 & High \\
\hline P6 & -6.80 & -6.90 & 401.98 & 1 & -3.925 & 9 & 0 & 95.78 & 95.78 & 10 & -3.85 & High \\
\hline P7 & -6.63 & -6.17 & 363.99 & 0.708 & -2.216 & 6 & 0 & 111.23 & 111.23 & 8 & -3.68 & High \\
\hline P8 & -6.84 & -7.42 & 363.99 & 0.497 & -2.216 & 6 & 0 & 111.23 & 111.23 & 8 & -3.68 & High \\
\hline P9 & -6.84 & -7.39 & 363.99 & 0.497 & -2.216 & 6 & 0 & 111.23 & 111.23 & 8 & -3.68 & High \\
\hline P10 & -6.02 & -4.43 & 409.98 & 0.714 & -2.003 & 6 & 0 & 154.37 & 154.37 & 9 & -3.76 & LOW \\
\hline P11 & -7.00 & -9.22 & 336.99 & 0.607 & -2.52 & 6 & 0 & 68.09 & 68.09 & 7 & -3.77 & High \\
\hline P12 & -7.08 & -9.17 & 336.99 & 0.396 & -2.52 & 6 & 0 & 68.09 & 68.09 & 7 & -3.77 & High \\
\hline P13 & -6.89 & -9.09 & 336.99 & 0.396 & -2.52 & 6 & 0 & 68.09 & 68.09 & 7 & -3.77 & High \\
\hline P14 & -7.05 & -9.06 & 352.96 & 1.068 & -2.061 & 6 & 0 & 68.09 & 68.09 & 7 & -4.21 & High \\
\hline P15 & -7.16 & -9.64 & 352.96 & 0.857 & -2.061 & 6 & 0 & 68.09 & 68.09 & 7 & -4.21 & High \\
\hline P16 & -7.19 & -9.39 & 352.96 & 0.857 & -2.061 & 6 & 0 & 68.09 & 68.09 & 7 & -4.21 & High \\
\hline P17 & -7.59 & -8.25 & 387.93 & 1.434 & -1.692 & 6 & 0 & 68.09 & 68.09 & 7 & -4.81 & High \\
\hline P18 & -7.27 & -9.16 & 329.99 & 1.305 & -1.983 & 6 & 0 & 68.09 & 68.09 & 7 & -3.91 & High \\
\hline P19 & -6.98 & -9.17 & 317.99 & 0.913 & -2.429 & 6 & 0 & 68.09 & 68.09 & 7 & -3.61 & High \\
\hline P20 & -7.32 & -9.65 & 396.91 & 1.033 & -1.977 & 6 & 0 & 68.09 & 68.09 & 7 & -4.52 & High \\
\hline
\end{tabular}




\section{Conclusion}

In general, PA derivatives were successfully synthesized using the Passerini multicomponent reaction. The compounds were entirely characterized by (IR, ${ }^{1} \mathrm{HNMR},{ }^{13} \mathrm{CNMR}$, Mass) spectrums. These PA derivatives were evaluated for cytotoxic activity against three different cell lines, including lung (A549), breast (MCF-7), and colon (HT-29) and one normal human lung cell line (MRC5). The findings of this study indicated satisfying selectivity of the compounds between the cancerous cell and non-cancerous cell line (MRC5). P5, and P16 have high efficacy in suppressing cell growth and considerably more potent in vitro cytotoxic activity than cisplatin and the others. Electrophoresis mobility shift assay revealed that P16 was able to ROS induce DNA cleavage in the presents of $\mathrm{H}_{2} \mathrm{O}_{2}(1.0 \mathrm{mM})$ in dose-dependent manner. P5, and P16 can significantly cause apoptosis in A549 cells via a dosedependent manner. The molecular docking studies of the synthesized compounds on Bcl-2 apoptosis regulator and DNA were also conducted and their interactions and further information on their molecular binding mechanism were acquired. These compounds (especially P5, and P16) have the ability to play an essential role in the future treatment of cancer diseases after further clinical studies.

\section{Methods And Experimental}

\subsection{General}

All chemical reagents and solvents were acquired from Merck Chemical or Sigma Aldrich. The passerine multicomponent reaction was used to synthesize the novel PA derivatives. To purify the product, the recrystallization process, which uses a combination of methanol and water, or chromatography plate, using 230-400 mesh silica gel and solution of $50 \%$ ethyl acetate and $50 \% n$-hexane, was applied. The advance of the reaction was monitored by TLC. It was conducted on silica gel polygrams SIL G/UV 254 plates. The analysis of the compound was recorded by IR spectra were run on a (Bruker's VERTEX 70 Series FTIR Spectrometers) and the ${ }^{1} \mathrm{H}$-NMR and ${ }^{13} \mathrm{C}$-NMR spectra were run on a Bruker Avance DPX 300, 500 FT-NMR spectrometers. Chemical shifts were reported in parts per million (ppm), down filed from tetramethylsilane coupling constant ( $($ ) values in $\mathrm{Hz}$, and spin multiplicities were denoted by the letters $\mathrm{s}$ (singlet), $\mathrm{d}$ (doublet), $\mathrm{t}$ (triplet), and $\mathrm{m}$ (multiple) (multiplet). Mass spectrum recorded by Manufacturer Company Agilent Technology - (HP)-MS Model: 5973).

\subsection{Synthesis of Pyrazinoic acid analogs}

Firstly, $1 \mathrm{mmol}$ of pyrazinoic acid was dissolved in $5 \mathrm{ml}$ of water by heating. Then $1 \mathrm{mmol}$ of aldehyde derivatives and $1.2 \mathrm{mmol}$ isocyanide were added to the reaction mixture, and stirred at room temperature for 4 to 48 hours. The solid obtained was washed with water and filtered and dried in a desiccator. For purification, recrystallization (methanol and water) or plate chromatography (silica gel with $50 \%$ ethyl acetate and $50 \% n$-hexane) was applied.

Below are the physical and spectral data of the synthesized compounds:

\subsubsection{2-(cyclohexylamino)-1-(2-methoxyphenyl)-2-oxoethyl pyrazine-2-carboxylate (P1)}

Yield: $77 \%$, mp: $134-136^{\circ} \mathrm{C}$, white solid. IR (KBr disk): (3272.91 ( $\mathrm{NH}$ amid group)), (3100.26-3029.84 (CH aromatic)), (2930.78-2854.42 ( $\mathrm{CH}$ aliphatic)), (1727.87 ( $\mathrm{C}=0$ ester)), (1655.64 ( $\mathrm{C}=0$ amid)), (1612.47-1458.08 ( $\mathrm{C}=\mathrm{C}$ aromatic)), (1274.32 (C-0)) cm $\mathrm{cm}^{-1} .^{1} \mathrm{H}$ NMR $\left(499 \mathrm{MHz}, \mathrm{DMSO}-\mathrm{d}_{6}\right) \delta\left(9.23(\mathrm{~s}, 1 \mathrm{H}) \mathrm{H}^{6}\right),\left(8.86(\mathrm{~d}, J=42.6 \mathrm{~Hz}, 3 \mathrm{H}) \mathrm{H}^{3^{\prime}}, \mathrm{H}^{2}\right)$, 
$(8.07(\mathrm{~d}, J=7.6 \mathrm{~Hz}, 1 \mathrm{H}) \mathrm{NH}),\left(7.39(\mathrm{t}, J=7.2 \mathrm{~Hz}, 1 \mathrm{H}) \mathrm{H}^{6},\left(7.17-6.85(\mathrm{~m}, 3 \mathrm{H})\left(\mathrm{H}^{3}, \mathrm{H}^{4}, \mathrm{H} 5\right),(6.46(\mathrm{~s}, 1 \mathrm{H}) \mathrm{CH}\right.\right.$ group, (3.81 $\left.(\mathrm{s}, 3 \mathrm{H}) \mathrm{H}(\mathrm{ome})^{[0]}\right),\left(3.60(\mathrm{~s}, 1 \mathrm{H}) \mathrm{H}^{1 ”}\right),\left(1.85-1.41(\mathrm{~m}, 6 \mathrm{H}) \mathrm{H}^{2 "}, \mathrm{H}^{6 "}, \mathrm{H}^{4^{\prime \prime}}\right),\left(1.18(\mathrm{q}, J=52.4,18.1,11.3,10.6 \mathrm{~Hz}, 3 \mathrm{H}) \mathrm{H}^{3^{\prime \prime}} \mathrm{H}^{5 "}\right)$.

${ }^{13} \mathrm{C}$ NMR $(126 \mathrm{MHz}$, dmso) $\delta$ 165.98, 162.79, 157.16, 148.15, 145.56, 144.74, 142.56, 130.31, 128.40, 123.24, $120.26,111.25,70.90,55.51,47.70,39.02,31.89,24.96,24.34$.

\subsubsection{2-(cyclohexylamino)-1-(3-methoxyphenyl)-2-oxoethyl pyrazine-2-carboxylate(P2)}

Yield: $80 \%$, mp: $173-175^{\circ} \mathrm{C}$, white solid. IR (KBr disk): (3272.91 (NH amid group)), (3100.26-3029.84 (CH aromatic)), (2930.78-2854.42 (CH aliphatic)), (1727.87 (C = O ester)), (1655.64 (C= O amid)), (1612.47-1458.08 (C = C aromatic)), (1274.32 (C-0)) $\mathrm{cm}^{-1}$. ${ }^{1} \mathrm{H}$ NMR (499 MHz, DMSO-d $) \delta\left(9.30(\mathrm{~s}, 1 \mathrm{H}) \mathrm{H}^{6},(8.90(\mathrm{dd}, J=35.3,1.7 \mathrm{~Hz}\right.$, $\left.3 \mathrm{H}) \mathrm{H}^{3^{\prime}, 2^{\prime}}\right),(8.27(\mathrm{~d}, J=7.6 \mathrm{~Hz}, 1 \mathrm{H}) \mathrm{NH}),\left(7.35(\mathrm{t}, J=8.0 \mathrm{~Hz}, 2 \mathrm{H}) \mathrm{H}^{5}\right),\left(7.17(\mathrm{~d}, J=7.4 \mathrm{~Hz}, 2 \mathrm{H}) \mathrm{H}^{2}\right),(7.04-6.88(\mathrm{~m}$, $\left.2 \mathrm{H}) \mathrm{H}^{4,6}\right),\left(6.09(\mathrm{~s}, 1 \mathrm{H}) \mathrm{CH}^{\star}\right),\left(3.77(\mathrm{~s}, 1 \mathrm{H}) \mathrm{H}^{1 "}\right),\left(3.52(\mathrm{~s}, 1 \mathrm{H}) \mathrm{H}^{1 "}\right),\left(1.85-1.41(\mathrm{~m}, 5 \mathrm{H}) \mathrm{H}^{2 "}, 4^{\prime \prime}, 6^{\prime \prime}\right),(1.35-0.98(\mathrm{~m}, 4 \mathrm{H})$ $\left.\mathrm{H}^{5,3 "}\right) .{ }^{13} \mathrm{C}$ NMR $(126 \mathrm{MHz}$, dmso) $\delta 166.74,163.22,159.65,148.85,146.29,145.45,143.14,137.39,130.09,119.95$, 114.39, 113.70, 76.65, 55.62, 48.23, 40.50, 40.34, 40.17, 40.00, 39.84, 39.67, 39.50, 32.68, 32.50, 25.59, $24.93,24.84$.

\subsubsection{2-(cyclohexylamino)-1-(4-methoxyphenyl)-2-oxoethyl pyrazine-2-carboxylate(P3)}

Yield: $83 \%$, mp: $182-184^{\circ} \mathrm{C}$, white solid. IR (KBr disk): (3252.47 (NH amid group)), (3080.85-3029.84 (CH aromatic)), (2929.16-2851.53 (CH aliphatic)), (1744.23 (C= O ester)), (1656.08 (C= O amid)), (1603.72-1463.43 (C= C aromatic)), (1261.32 (C-0)) cm ${ }^{-1} .{ }^{1} \mathrm{H}$ NMR $\left(300 \mathrm{MHz}, \mathrm{DMSO}-d_{6}\right) \delta\left(9.21(\mathrm{~d}, J=29.2 \mathrm{~Hz}, 1 \mathrm{H}) \mathrm{H}^{6}\right),(8.98-8.58(\mathrm{~m}, 4 \mathrm{H})$ $\left.\mathrm{H}^{3}, \mathrm{H}^{2}\right),(8.21(\mathrm{~d}, J=7.4 \mathrm{~Hz}, 1 \mathrm{H}) \mathrm{NH}),\left(7.50(\mathrm{~d}, J=8.3 \mathrm{~Hz}, 2 \mathrm{H}) \mathrm{H}^{2}, \mathrm{H}^{6}\right),\left(6.97(\mathrm{~d}, J=8.3 \mathrm{~Hz}, 2 \mathrm{H}) \mathrm{H}^{5}, \mathrm{H}^{3}\right),\left(6.05(\mathrm{~s}, 1 \mathrm{H}) \mathrm{CH}^{*}\right.$ group), (3.50 (s, 3H) H ome $\left.{ }^{[P]}\right),\left(1.86-1.38(\mathrm{~m}, 6 \mathrm{H}) \mathrm{H}^{1 ", 2 ", 4 ", 6 "}\right),\left(1.36-0.77(\mathrm{~m}, 3 \mathrm{H}) \mathrm{H}^{5^{\prime \prime}, 3^{\prime \prime} .}{ }^{13} \mathrm{C} \mathrm{NMR}(75 \mathrm{MHz}, \mathrm{DMSO}) \delta\right.$ $166.65,162.83,159.57,148.33,145.78,145.53,144.95,144.49,142.73,129.03,127.47,113.84,76.07,55.19,47.71$, $40.33,40.05,39.77,39.49,39.21,38.93,38.65,32.23,25.12,24.48$.

\subsubsection{2-(cyclohexylamino)-1-(3,4-dimethoxyphenyl)-2-oxoethyl pyrazine-2-carboxylate(P4)}

Yield: 47\%, mp: 192-193 ${ }^{\circ} \mathrm{C}$, white solid. IR (KBr disk): (3266.25 (NH amid group)), (3098.33-3029.84 (CH aromatic)), (2928.16-2852.96 (CH aliphatic)), (1746.36 (C= O ester)), (1655.67 (C= O amid)), (1593.12-1563.43 (C = C aromatic)), (1258.88 (C-0)) cm ${ }^{-1} .{ }^{1} \mathrm{H}$ NMR (499 MHz, DMSO-d6) $\delta\left(9.28(\mathrm{~s}, 1 \mathrm{H}) \mathrm{h}^{6^{\prime}},\left(8.88(\mathrm{~d}, J=36.9 \mathrm{~Hz}, 2 \mathrm{H}) \mathrm{H}^{3^{\prime}, 2^{\prime}}\right)\right.$, $(8.18(\mathrm{~d}, J=7.7 \mathrm{~Hz}, 1 \mathrm{H}) \mathrm{NH}),\left(7.26-7.04(\mathrm{~m}, 3 \mathrm{H}) \mathrm{H}^{2,5}\right),\left(6.99(\mathrm{~d}, J=8.2 \mathrm{~Hz}, 1 \mathrm{H}) \mathrm{H}^{6}\right),\left(6.04(\mathrm{~s}, 1 \mathrm{H}) \mathrm{CH}^{\star}\right),(3.76(\mathrm{~s}, 6 \mathrm{H}) \mathrm{H}$ ome $\left.{ }^{[\mathrm{acc}]}\right),\left(3.33(\mathrm{~s}, 1 \mathrm{H}) \mathrm{H}^{1 "}\right),\left(1.90-1.43(\mathrm{~m}, 6 \mathrm{H}) \mathrm{H}^{2 ", 4 ", 6 "},\left(1.33-0.85(\mathrm{~m}, 3 \mathrm{H}) \mathrm{H}^{5 ", 3 "}\right) .{ }^{13} \mathrm{C} \mathrm{NMR}(126 \mathrm{MHz}, \mathrm{dmso}) \delta\right.$ $167.01,163.26,149.68,148.99,148.77,146.25,145.41,143.22,128.14,120.71,112.05,111.82,76.75,56.02,55.99$, $48.18,40.49,40.32,40.15,39.98,39.82,39.65,39.48,32.67,32.52,25.59,24.95,24.87$. Elemental analysis calcd (\%) for $\mathrm{C}_{21} \mathrm{H}_{25} \mathrm{~N}_{3} \mathrm{O}_{5}$ (399.18):C,63.14; H,6.31; N,10.52;found: C,63.26; H,6.43;N,10.64.

\subsubsection{2-(cyclohexylamino)-1-(2,5-dimethoxyphenyl)-2-oxoethyl pyrazine-2-carboxylate(P5)}

Yield: $49 \%$, mp: $114-117^{\circ} \mathrm{C}$, white solid. IR (KBr disk): (3266.25 (NH amid group)), (3098.33-3029.84 (CH aromatic)), (2928.16-2852.96 (CH aliphatic)), (1746.36 (C= O ester)), (1655.67 (C= O amid)), (1593.12-1563.43 (C= C aromatic)), (1258.88 (C-0)) cm ${ }^{-1}$. ${ }^{1} \mathrm{H}$ NMR $(300 \mathrm{MHz}, \mathrm{DMSO}-\mathrm{d} 6) \delta\left(9.23(\mathrm{~d}, \mathrm{~J}=1.3 \mathrm{~Hz}, 1 \mathrm{H}) \mathrm{H}^{6^{\prime}},(9.02-8.73(\mathrm{~m}, 2 \mathrm{H})\right.$ 
$\left.H^{3^{\prime}, 2^{\prime}}\right),(8.10(\mathrm{~d}, J=7.9 \mathrm{~Hz}, 1 \mathrm{H}) \mathrm{NH}),\left(7.27-6.79(\mathrm{~m}, 4 \mathrm{H}) \mathrm{H}^{4,3,6}\right),\left(6.41(\mathrm{~s}, 1 \mathrm{H}) \mathrm{CH}^{*}\right),\left(3.76(\mathrm{~s}, 6 \mathrm{H}) \mathrm{H}^{\mathrm{a}, \mathrm{c}}, 3.34(\mathrm{~s}, 1 \mathrm{H}) \mathrm{H}^{1 "}\right)$, $\left(1.84-1.43(\mathrm{~m}, 5 \mathrm{H}) \mathrm{H}^{2 ", 4 " 6 " 6)}\right),\left(1.18(\mathrm{dq}, J=29.0,8.6 \mathrm{~Hz}, 4 \mathrm{H}) \mathrm{H}^{5^{\prime \prime}, 3^{\prime \prime}}\right) .{ }^{13} \mathrm{C}$ NMR $(75 \mathrm{MHz}, \mathrm{DMSO}) \delta$ 166.04, 162.92, $153.00,151.44,148.38,145.79,144.94,142.65,124.28,114.73,114.50,112.62,70.99,56.25,56.19,55.49,47.86$, $40.33,40.05,39.78,39.50,39.22,38.94,38.67,32.09,25.11,24.55$.

\subsubsection{2-(cyclohexylamino)-2-oxo-1-(2,4,6-trimethoxyphenyl)ethyl pyrazine-2-carboxylate(P6)}

Yield: 55\%, mp: $99-100^{\circ} \mathrm{C}$, white solid. IR (KBr disk): (3266.25 ( $\mathrm{NH}$ amid group)), (3098.33-3029.84 (CH aromatic)), (2928.16-2852.96 (CH aliphatic)), (1746.36 (C= O ester)), (1655.67 (C= O amid)), (1593.12-1563.43 (C= C aromatic)), (1258.88 (C-0)) cm ${ }^{-1} .{ }^{1} \mathrm{H}$ NMR (499 MHz, DMSO-d6) $\delta\left(10.33(\mathrm{~s}, 1 \mathrm{H}) \mathrm{H}^{6^{\prime}}\right),\left(9.23(\mathrm{~s}, 1 \mathrm{H}) \mathrm{H} 3^{\prime}\right),(8.86(\mathrm{~d}, J=$ $\left.43.7 \mathrm{~Hz}, 1 \mathrm{H}) \mathrm{H}^{2}\right),(7.56(\mathrm{~d}, J=8.1 \mathrm{~Hz}, 1 \mathrm{H}) \mathrm{NH}),\left(7.37-7.07(\mathrm{~m}, 3 \mathrm{H}) \mathrm{H}^{3}\right),\left(6.94-6.71(\mathrm{~m}, 1 \mathrm{H}) \mathrm{H}^{5}\right),(6.40(\mathrm{~s}, 1 \mathrm{H}) \mathrm{NH})$, $\left(5.84(\mathrm{~d}, J=5.4 \mathrm{~Hz}, 1 \mathrm{H}) \mathrm{CH}^{\star}\right),\left(5.13(\mathrm{~d}, J=5.3 \mathrm{~Hz}, 2 \mathrm{H}) \mathrm{H}^{5}\right),\left(3.99-3.56(\mathrm{~m}, 9 \mathrm{H}) \mathrm{H}^{\mathrm{a}, \mathrm{b}, \mathrm{c}}\right)$ overlapping multiple), (3.62$\left.3.49(\mathrm{~m}, 1 \mathrm{H}) \mathrm{H}^{1 "},\left(1.60(\mathrm{~d}, J=68.4 \mathrm{~Hz}, 3 \mathrm{H}) \mathrm{H}^{2 "}, 4^{\prime \prime}, 6^{\prime \prime}\right), 1.19(\mathrm{~d}, J=62.3 \mathrm{~Hz}, 2 \mathrm{H}) \mathrm{H}^{5^{\prime \prime}, 3^{\prime \prime}}\right) .{ }^{13} \mathrm{C}$ NMR $(126 \mathrm{MHz}, \mathrm{dmso}) \delta$ 189.30, 171.43, 153.52, 151.34, 131.43, 124.77, 123.58, 114.90, 114.30, 113.52, 112.83, 110.70, 68.29, 56.81, 56.58, $56.01,55.93,55.77,47.63,40.49,40.32,40.15,39.98,39.82,39.65,39.48,32.80,32.61,25.59,25.11,25.07$. Elemental analysis calcd (\%) for $\mathrm{C}_{22} \mathrm{H}_{27} \mathrm{~N}_{3} \mathrm{O}_{6}$ (429.19):C,61.53; H,6.34; N,9.78;found: C,61.54; $\mathrm{H}, 6.44 ; \mathrm{N}, 10.65$.

\subsubsection{2-(cyclohexylamino)-1-(2-nitrophenyl)-2-oxoethyl pyrazine- 2-carboxylate(P7)}

Yield: $84 \%$, mp: $160-162^{\circ} \mathrm{C}$, white solid. IR (KBr disk): (3285.07 (NH amid group)), (3093.62-3029.84 (CH aromatic)), (2931.26-2855.74 (CH aliphatic)), (1730.45 (C= O ester)), (1656.67 ( $\mathrm{C}=0$ amid)), (1527.37-1559.44 (C= C aromatic)), (1279.34 (C-0)) cm ${ }^{-1}$. ${ }^{1} \mathrm{H}$ NMR (499 MHz, DMSO-d6) $\delta\left(9.27(\mathrm{~s}, 1 \mathrm{H}) \mathrm{H}^{6^{\prime}},\left(8.90(\mathrm{~d}, J=40.8 \mathrm{~Hz}, 2 \mathrm{H}) \mathrm{H}^{3^{\prime}, 2^{\prime}}\right)\right.$, $(8.33(\mathrm{~d}, J=7.4 \mathrm{~Hz}, 1 \mathrm{H}) \mathrm{NH}),\left(8.11(\mathrm{~d}, J=7.9 \mathrm{~Hz}, 1 \mathrm{H}) \mathrm{H}^{3}\right),\left(7.93-7.54(\mathrm{~m}, 3 \mathrm{H}) \mathrm{H}^{4,5,6}\right),\left(6.79(\mathrm{~s}, 1 \mathrm{H}) \mathrm{CH}^{*},(3.59(\mathrm{~s}, 1 \mathrm{H})\right.$ $\left.\mathrm{H}^{1 "}\right),\left(1.90-1.41(\mathrm{~m}, 6 \mathrm{H}) \mathrm{H}^{6 "}, 4^{\prime \prime}, 2^{\prime \prime}\right),(1.17$ (ddd, $\left.J=44.4,20.7,10.0 \mathrm{~Hz}, 4 \mathrm{H}) \mathrm{H}^{3^{\prime \prime}, 5^{\prime \prime}}\right) .{ }^{13} \mathrm{C}$ NMR $(126 \mathrm{MHz}, \mathrm{dmso}) \delta 165.40$, 163.06, 149.00, 146.36, 145.49, 142.83, 134.48, 130.70, 130.36, 129.77, 125.43, 72.18, 48.61, 40.32, 40.15, 39.98, 39.82, 39.65, 32.51, 32.47, 25.56, 24.88, 24.83.

\subsubsection{2-(cyclohexylamino)-1-(3-nitrophenyl)-2-oxoethyl pyrazine- 2-carboxylate(P8)}

Yield: $90 \%$, mp: $163-165^{\circ} \mathrm{C}$, white solid. IR (KBr disk): (3285.07 (NH amid group)), (3093.62-3029.84 (CH aromatic)), (2931.26-2855.74 (CH aliphatic)), (1730.45 (C= O ester)), (1656.67 (C= O amid)), (1527.37-1559.44 (C= C aromatic)), (1279.34 (C-0)) cm ${ }^{-1}$. ${ }^{1} \mathrm{H}$ NMR (499 MHz, DMSO-d6) $\delta\left(9.39-9.13(\mathrm{~m}, 1 \mathrm{H}) \mathrm{H}^{6^{\prime}}\right),(8.92(\mathrm{dt}, \mathrm{J}=34.5,1.5 \mathrm{~Hz}$, $3 \mathrm{H}) \mathrm{H}^{3^{\prime}, 2^{\prime}},\left(8.47(\mathrm{~d}, J=12.4 \mathrm{~Hz}, 1 \mathrm{H}) \mathrm{H}^{2}\right),\left(8.27(\mathrm{~d}, J=8.2 \mathrm{~Hz}, 1 \mathrm{H}) \mathrm{H}^{4}\right),(8.08(\mathrm{~d}, J=7.5 \mathrm{~Hz}, 1 \mathrm{H}) \mathrm{NH}),(7.87-7.62(\mathrm{~m}, 2 \mathrm{H})$ $\left.\mathrm{H}^{6,5}\right),\left(6.30(\mathrm{~s}, 1 \mathrm{H}) \mathrm{CH}^{*}\right.$ group, $\left(3.53(\mathrm{~s}, 1 \mathrm{H}) \mathrm{H}^{1 "}\right),\left(1.94-1.39(\mathrm{~m}, 6 \mathrm{H}) \mathrm{H}^{6 "}, 4^{\prime \prime}, 2^{\prime \prime}\right),\left(1.41-0.86(\mathrm{~m}, 3 \mathrm{H}) \mathrm{H}^{5^{\prime \prime}, 3^{\prime \prime}}\right) .{ }^{13} \mathrm{C} N M R(126$ $\mathrm{MHz}$, dmso) $\delta 166.18,163.06,148.98,148.23,146.40,145.49,142.93,138.05,134.27,130.75,124.14,122.45$, 75.57, 48.34, 40.51, 40.34, 40.26, 40.17, 40.01, 39.84, 39.67, 39.51, 32.62, 32.41, 25.56, 24.85, 24.75. Elemental analysis calcd (\%) for $\mathrm{C}_{19} \mathrm{H}_{20} \mathrm{~N}_{4} \mathrm{O}_{5}$ (384.39):C, 59.37; $\mathrm{H}, 5.24 ; \mathrm{N}, 14.58 ; f$;ound: C,58.43; $\mathrm{H}, 4.30 ; \mathrm{N} 13.64$.

\subsubsection{2-(cyclohexylamino)-1-(4-nitrophenyl)-2-oxoethyl pyrazine- 2-carboxylate(P9)}


Yield: $85 \%$, mp: $200-202^{\circ} \mathrm{C}$, white solid. IR (KBr disk): (3285.07 (NH amid group)), (3093.62-3029.84 (CH aromatic)), (2931.26-2855.74 (CH aliphatic)), (1730.45 (C= O ester)), (1656.67 (C= O amid)), (1527.37-1559.44 (C= C aromatic)), (1279.34 (C-0)) cm ${ }^{-1} .{ }^{1} \mathrm{H}$ NMR (499 MHz, DMSO-d6) $\delta\left(9.34(\mathrm{~s}, 1 \mathrm{H}) \mathrm{H}^{6^{\prime}},\left(8.90(\mathrm{~d}, J=35.1 \mathrm{~Hz}, 2 \mathrm{H}) \mathrm{H}^{3^{\prime}, 2^{\prime}}\right)\right.$, (8.37 (dd, J=77.1, 7.9 Hz, 3H) H $\left.\mathrm{H}^{5,3}, \mathrm{NH}\right),\left(7.89(\mathrm{~d}, J=8.2 \mathrm{~Hz}, 2 \mathrm{H}) \mathrm{H}^{6,2}\right),\left(6.28(\mathrm{~s}, 1 \mathrm{H}) \mathrm{CH}^{\star}\right),\left(3.51(\mathrm{~s}, 2 \mathrm{H}) \mathrm{H}^{1},(1.81-1.33\right.$ $(\mathrm{m}, 6 \mathrm{H}) \mathrm{H}^{\left.4 ", 6 ", 2^{\prime \prime}\right)},\left(1.33-0.85(\mathrm{~m}, 3 \mathrm{H}) \mathrm{H}^{5 ", 3 "}\right) .{ }^{13} \mathrm{C} \mathrm{NMR}(126 \mathrm{MHz}, \mathrm{dmso}) \delta 165.96,162.99,148.97,148.07,146.40$, $145.48,143.09,142.89,128.80,124.14,75.76,48.37,40.48,40.31,40.15,39.98,39.81,39.65,39.48,32.62,32.39$, 25.54, 24.84, 24.75.

\subsubsection{2-(cyclohexylamino)-1-(2,4-dinitrophenyl)-2-oxoethyl pyrazine-2-carboxylate(P10)}

Yield: 88\%, mp: 197-199 $\mathrm{C}$, white solid. IR (KBr disk): (3334.18 (NH amid group)), (3106.15 (CH aromatic)), (2937.88-2856.13 (CH aliphatic)), (1744.38 (C = O ester)), (1681. (C = 0 amid)), (1538.43 ( $\mathrm{NO}_{2}$ symmetric stretch)), (1538.43-1450.11 (C = C aromatic)), (1348.34 ( $\mathrm{NO}_{2}$ asymmetric stretch)), (1224.20 (C-O ester)) cm ${ }^{-1}$. ${ }^{1} \mathrm{H} \mathrm{NMR}^{(499}$ MHz, DMSO- $\left.d_{6}\right) \delta\left(9.31(\mathrm{~s}, 1 \mathrm{H}) \mathrm{H}^{6^{\prime}},\left(9.09-8.69(\mathrm{~m}, 3 \mathrm{H}) \mathrm{H}^{2^{\prime}, 3^{\prime}, 3}\right),\left(8.57(\mathrm{~d}, J=8.5 \mathrm{~Hz}, 1 \mathrm{H}) \mathrm{H}^{5}\right),(8.43(\mathrm{~d}, J=7.5 \mathrm{~Hz}, 1 \mathrm{H})\right.$ $\mathrm{NH}),\left(8.01(\mathrm{~d}, J=8.6 \mathrm{~Hz}, 1 \mathrm{H}) \mathrm{H}^{6}\right),\left(6.92(\mathrm{~s}, 1 \mathrm{H}) \mathrm{CH}^{\star}\right),\left(3.58(\mathrm{~s}, 1 \mathrm{H}) \mathrm{H}^{1 "}\right),\left(1.98-1.41(\mathrm{~m}, 7 \mathrm{H}) \mathrm{H}^{2 \prime}, 4^{\prime \prime}, 6^{\prime \prime}\right), 1.18(\mathrm{ddd}, J=$ 44.5, 20.2, 9.3 Hz, 3H) $\left.\mathrm{H}^{5 " 3} 3^{\prime \prime}\right) .{ }^{13} \mathrm{C}$ NMR $(126 \mathrm{MHz}$, dmso) $\delta 164.56,162.91,149.08,148.79,148.07,146.54,145.52$, 142.70, 136.69, 131.23, 128.50, 120.75, 71.88, 48.82, 40.31, 40.14, 39.97, 39.81, 39.64, 32.47, 32.44, 25.54, 24.86. Elemental analysis calcd (\%) for $\mathrm{C}_{19} \mathrm{H}_{19} \mathrm{~N}_{5} \mathrm{O}_{7}$ (429.19):C,53.15; H,4.46; N,16.31;found: C,53.22;H,4.53;N,16.38.

\subsubsection{2-(cyclohexylamino)-1-(2-fluorophenyl)-2-oxoethyl pyrazine-2-carboxylate(P11)}

Yield: 55\%, mp: $143-145^{\circ} \mathrm{C}$, white solid. IR (KBr disk): (3265.97 (NH amid group)), (3100.43 (CH aromatic)), (2930.03-2854.01 (CH aliphatic)), (1718.87 (C= O ester)), (1656.95 (C= O amid)), (1569.89-1510.03 (C= C aromatic)), (1187.89 (C-0)), (C-F (967.65)) cm-1. ${ }^{1} \mathrm{H}$ NMR (499 MHz, DMSO-d6) $\delta\left(9.26(\mathrm{~s}, 1 \mathrm{H}) \mathrm{H}^{6^{\prime}}, 8.87\right.$ (d, J= 43.6 $\left.\mathrm{Hz}, 2 \mathrm{H}) \mathrm{H}^{3^{\prime} .2^{\prime}}\right),(8.28(\mathrm{~d}, J=7.6 \mathrm{~Hz}, 1 \mathrm{H}) \mathrm{NH}),\left(7.68-7.40(\mathrm{~m}, 1 \mathrm{H}) \mathrm{H}^{5}\right),\left(7.36-7.06(\mathrm{~m}, 1 \mathrm{H}) \mathrm{H}^{6}\right),\left(6.40(\mathrm{~s}, 1 \mathrm{H}) \mathrm{CH}^{\star}\right)$,

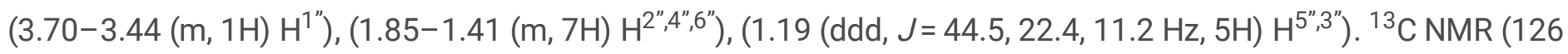
$\mathrm{MHz}$, dmso) $\delta$ 165.74, 163.18, 161.73, 159.76, 148.90, 146.32, 145.40, 142.94, 131.78, 131.72, 130.12, 125.16, $123.30,123.19,116.20,116.03$, 70.68, 48.46, 40.49, 40.32, 40.15, 39.98, 39.82, 39.65, 39.48, 32.54, 32.49, 25.57, 24.98, 24.93. Elemental analysis calcd (\%) for $\mathrm{C}_{19} \mathrm{H}_{20} \mathrm{FN}_{3} \mathrm{O}_{3}$ (357.15):C,63.85; $\mathrm{H}, 5.64 ; \mathrm{N}, 11.76$; found: $\mathrm{C}, 63.90 ; \mathrm{H}, 5.69 ; \mathrm{N}, 11.81$.

\subsubsection{2-(cyclohexylamino)-1-(3-fluorophenyl)-2-oxoethyl pyrazine-2-carboxylate(P12)}

Yield: $54 \%$, mp: $143-145^{\circ} \mathrm{C}$, white solid. IR (KBr disk): (3265.97 (NH amid group)), (3100.43 (CH aromatic)), (2930.03-2854.01 (CH aliphatic)), (1718.87 (C = O ester)), (1656.95 (C= O amid)), (1569.89-1510.03 (C = C aromatic)), (1187.89 (C-0)), (C-F (967.65)) cm ${ }^{-1} .{ }^{1} \mathrm{H}$ NMR (499 MHz, DMSO-d6) $\delta\left(9.32(\mathrm{~s}, 1 \mathrm{H}) \mathrm{H}^{6}\right),(9.18(\mathrm{~s}, 3 \mathrm{H}))$ $H^{\text {Ring }(A, B)}$ overlapping multiple), (9.04-8.70 (m, 3H) $\left.\mathrm{H}^{2,} 3^{\prime}, 5\right),(8.30(\mathrm{dd}, J=19.1,7.9 \mathrm{~Hz}, 1 \mathrm{H}) \mathrm{NH}),(7.46(\mathrm{dq}, J=21.6$, 11.4, 9.4 Hz, 2H) $\left.\left.\mathrm{H}^{6,4}\right), 7.23(\mathrm{t}, J=7.6 \mathrm{~Hz}, 1 \mathrm{H}) \mathrm{H}^{2}\right),\left(6.14(\mathrm{~s}, 1 \mathrm{H}) \mathrm{CH}^{\star}\right),\left(1.87-1.41(\mathrm{~m}, 5 \mathrm{H}) \mathrm{H}^{1 "}, 2^{\prime \prime}, 6^{\prime \prime}\right),(1.42-0.90(\mathrm{~m}, 3 \mathrm{H})$ $\left.\mathrm{H}^{5 ", 3 "}\right) .{ }^{13} \mathrm{C}$ NMR $(126 \mathrm{MHz}$, dmso) $\delta 166.43,163.10,161.44,148.89,148.13,146.35,146.02,145.45,145.07,143.00$, $138.62,138.56,131.08,131.01,123.75,116.08,115.92,114.61,114.43,75.94,48.27,40.48,40.31,40.15,39.98$, $39.81,39.65,39.48,32.62,32.43,25.55,24.87,24.78$.

\subsubsection{2-(cyclohexylamino)-1-(4-fluorophenyl)-2-oxoethyl pyrazine-2-carboxylate(P13)}


Yield: $56 \%$, mp: $180-182^{\circ} \mathrm{C}$, white solid. IR (KBr disk): (3265.97 (NH amid group)), (3100.43 (CH aromatic)), (2930.03-2854.01 (CH aliphatic)), (1718.87 (C= O ester)), (1656.95 (C= O amid)), (1569.89-1510.03 (C= C

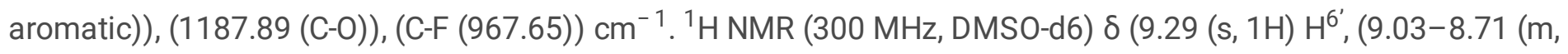
$\left.2 \mathrm{H}) \mathrm{H}^{2,3}\right),\left(8.39-8.21(\mathrm{~m}, 2 \mathrm{H}) \mathrm{H}^{2}\right),(8.09(\mathrm{dd}, J=8.4,5.7 \mathrm{~Hz}, 1 \mathrm{H}) \mathrm{NH}),\left(7.64(\mathrm{dd}, J=7.6,4.7 \mathrm{~Hz}, 2 \mathrm{H}) \mathrm{H}^{6}\right),(7.47-7.12$ $\left.(\mathrm{m}, 3 \mathrm{H}) \mathrm{H}^{3,5}\right)$ overlapping multiple), $\left.\left(6.09(\mathrm{~d}, J=22.8 \mathrm{~Hz}, 1 \mathrm{H}) \mathrm{CH}^{*}\right), 3.50(\mathrm{~s}, 1 \mathrm{H}) \mathrm{H}^{1 "}\right),\left(2.15-1.38(\mathrm{~m}, 4 \mathrm{H}) \mathrm{H}^{2 \prime, 4 ", 6 "}\right)$, (1.12 (dd, $\left.J=30.1,19.4 \mathrm{~Hz}, 3 \mathrm{H}) \mathrm{H}^{3 \prime \prime}, 5^{\prime \prime}\right) .{ }^{13} \mathrm{C}$ NMR (75 MHz, DMSO) $\delta 166.67,166.34,163.99,163.88,162.73,160.63$, $148.41,145.85,144.97,142.61,132.26,131.85,131.81,129.59,125.79,116.10,115.80,115.53,115.24,75.57$, $74.95,47.75,40.33,40.06,39.78,39.50,39.22,38.94,38.67,32.20,32.00,25.10,24.43$.

\subsubsection{1-(2-chlorophenyl)-2-(cyclohexylamino)-2-oxoethyl pyrazine-2-carboxylate(P14)}

Yield: $48 \%$, mp: $138-139^{\circ} \mathrm{C}$, white solid. IR (KBr disk): (3308.64 (NH amid group)), (3061.78-3029.67 (CH aromatic)), (2938.15-2850.61 (CH aliphatic)), (1738.85(C = O ester)), (1649.84(C = 0 amid)), (1536.92-1449.65 (C = C aromatic)), (1133.88 (C-0)), (755.87 (C-Cl)) cm ${ }^{-1}$. ${ }^{1} \mathrm{H}$ NMR (499 MHz, DMSO-d6) $\delta\left(8.33(\mathrm{~d}, J=7.7 \mathrm{~Hz}, 1 \mathrm{H}) \mathrm{H}^{6}\right),(7.86(\mathrm{~d}, J=8.0$ $\left.\mathrm{Hz}, 2 \mathrm{H}) \mathrm{H}^{3^{\prime}, 2^{\prime}}\right),\left(7.71-7.23(\mathrm{~m}, 6 \mathrm{H}) \mathrm{H}^{3,4,5,6}, \mathrm{NH}\right.$ overlapping multiple), $\left(6.40(\mathrm{~s}, 1 \mathrm{H}) \mathrm{CH}^{\star}\right),\left(5.24(\mathrm{~s}, 1 \mathrm{H}) \mathrm{H}^{1^{\prime \prime}}\right),(1.66(\mathrm{ddd}, \mathrm{J}$ $\left.=74.7,41.4,13.2 \mathrm{~Hz}, 6 \mathrm{H}) \mathrm{H}^{2 ", 4 ", 6 "}\right),(1.20$ (dq, $\left.J=54.4,14.5,12.0 \mathrm{~Hz}, 3 \mathrm{H}) \cdot \mathrm{H}^{5^{\prime \prime}, 3^{\prime \prime}}\right) .{ }^{13} \mathrm{C} \mathrm{NMR}(126 \mathrm{MHz}, \mathrm{dmso}) \delta 165.77$, $164.27,134.21,134.13,133.69,131.93,131.43,131.22$, 130.14, 130.03, 129.45, 128.01, 127.93, 73.40, 48.47, 40.49, $40.32,40.15,39.99,39.82,39.65,39.49,32.51,25.58,24.91$.

\subsubsection{1-(3-chlorophenyl)-2-(cyclohexylamino)-2-oxoethyl pyrazine-2-carboxylate(P15)}

Yield: $49 \%$, mp: $139-141^{\circ} \mathrm{C}$, white solid. IR ( $\mathrm{KBr}$ disk): (3308.64 (NH amid group)), (3061.78-3029.67 (CH aromatic)), (2938.15-2850.61 (CH aliphatic)), (1738.85(C = O ester)), (1649.84(C = O amid)), (1536.92-1449.65 (C = C aromatic)), (1133.88 (C-0)), (755.87 (C-Cl)) cm ${ }^{-1}$. ${ }^{1} \mathrm{H}$ NMR (300 MHz, DMSO-d 6 ) $\delta\left(9.31(\mathrm{~d}, J=1.3 \mathrm{~Hz}, 1 \mathrm{H}) \mathrm{H}^{6^{\prime}}\right),(9.04-8.77(\mathrm{~m}$, $\left.2 \mathrm{H}) \mathrm{H}^{3^{\prime} .2^{\prime}}\right),(8.36(\mathrm{~d}, J=7.8 \mathrm{~Hz}, 1 \mathrm{H}) \mathrm{NH}),\left(7.78-7.32(\mathrm{~m}, 4 \mathrm{H}) \mathrm{H}^{2,4,5,6}\right.$ overlapping multiple), $\left(6.13(\mathrm{~s}, 1 \mathrm{H}) \mathrm{CH}^{\star},(3.66-\right.$ $\left.3.44(\mathrm{~m}, 1 \mathrm{H}) \mathrm{H}^{1 "}\right),\left(1.84-1.35(\mathrm{~m}, 6 \mathrm{H}) \mathrm{H}^{2 "}, 4^{\prime \prime}, 6^{\prime \prime}\right),(1.15$ (ddd, $\left.J=43.8,19.5,9.6 \mathrm{~Hz}, 4 \mathrm{H}) \mathrm{H}^{5 ", 3 "}\right) .{ }^{13} \mathrm{C} \mathrm{NMR}(75 \mathrm{MHz}$, DMSO) $\delta 165.96,162.66,148.47,145.89,144.99,142.51,137.83,133.05,130.49,128.69,127.15,127.04,125.92$, $75.46,47.81,40.33,40.06,39.78,39.50,39.22,38.94,38.67,32.16,25.10,24.41$.

\subsubsection{1-(4-chlorophenyl)-2-(cyclohexylamino)-2-oxoethyl pyrazine-2-carboxylate(P16)}

Yield: $49 \%$, mp: $139-141^{\circ} \mathrm{C}$, white solid. IR (KBr disk): (3308.64 (NH amid group)), (3061.78-3029.67 (CH aromatic)), (2938.15-2850.61 (CH aliphatic)), (1738.85(C = O ester)), (1649.84(C= 0 amid)), (1536.92-1449.65 (C = C aromatic)), (1133.88 (C-0)), (755.87 (C-Cl)) cm ${ }^{-1}$. ${ }^{1} \mathrm{H}$ NMR (300 MHz, DMSO-d6) $\delta\left(9.30(\mathrm{~s}, 1 \mathrm{H}) \mathrm{H}^{6^{\prime}}\right),(8.88(\mathrm{~d}, \mathrm{~J}=20.6 \mathrm{~Hz}, 2 \mathrm{H})$ $\left.\mathrm{H}^{3^{\prime}, 2^{\prime}}\right),(8.33(\mathrm{~d}, J=7.6 \mathrm{~Hz}, 1 \mathrm{H}) \mathrm{NH}),\left(7.80-7.30(\mathrm{~m}, 4 \mathrm{H}) \mathrm{H}^{2,3,5.6}\right.$ overlapping multiple), $\left(6.13(\mathrm{~s}, 1 \mathrm{H}) \mathrm{CH}^{\star}\right),(3.50(\mathrm{~s}, 1 \mathrm{H})$

$\left.\mathrm{H}^{1 "}\right),\left(1.93-1.44(\mathrm{~m}, 7 \mathrm{H}) \mathrm{H}^{2 ", 4 ", 6 "}\right),\left(1.43-0.87(\mathrm{~m}, 3 \mathrm{H}) \mathrm{H}^{5 ", 3 "}\right) .{ }^{13} \mathrm{C}$ NMR $(75 \mathrm{MHz}, \mathrm{DMSO}) \delta 166.10,162.66,148.41$, 145.85, 144.97, 142.54, 134.50, 133.40, 129.18, 128.53, 75.49, 47.76, 40.32, 40.04, 39.76, 39.48, 39.20, 38.93, 38.65, 32.17, 31.97, 25.09, 24.39. Elemental analysis calcd (\%) for $\mathrm{C}_{19} \mathrm{H}_{20} \mathrm{ClN}_{3} \mathrm{O}_{3}$ (373.12):C,61.04; $\mathrm{H}, 5.39 ; \mathrm{N}, 11.24$;found: $\mathrm{C}, 61.12 ; \mathrm{H}, 5.47 ; \mathrm{N}, 11.32$.

\subsubsection{2-(cyclohexylamino)-1-(2,4-dichlorophenyl)-2-oxoethyl pyrazine-2-carboxylate(P17)}

Yield: $77 \%$, mp: $164-166^{\circ} \mathrm{C}$, white solid. IR (KBr disk): (3325.35 (NH amid group)), (3061.78-3029.67 (CH aromatic)), (2938.15-2850.61 (CH aliphatic)), (1738.85(C = O ester)), (1649.84(C= O amid)), (1536.92-1449.65 (C= C aromatic)), (1133.88 (C-O)), (755.87 (C-Cl)) cm ${ }^{-1} .{ }^{1} \mathrm{H}$ NMR (499 MHz, DMSO-d 6 ) $\delta\left(9.26(\mathrm{~s}, 1 \mathrm{H}) \mathrm{H}^{6^{\prime}}\right),\left(9.03-8.78(\mathrm{~m}, 2 \mathrm{H}) \mathrm{H}^{3^{\prime}, 2^{\prime}}\right)$, 
$\left.(8.36(\mathrm{~d}, J=7.7 \mathrm{~Hz}, 1 \mathrm{H}) \mathrm{NH}),\left(7.72(\mathrm{~s}, 1 \mathrm{H}) \mathrm{H}^{3}\right),\left(7.53(\mathrm{q}, J=8.7 \mathrm{~Hz}, 2 \mathrm{H}) \mathrm{H}^{6,5}\right),\left(6.44(\mathrm{~s}, 1 \mathrm{H}) \mathrm{CH}^{*}\right), 3.61(\mathrm{~s}, 1 \mathrm{H}) \mathrm{H}^{1 "}\right)$,

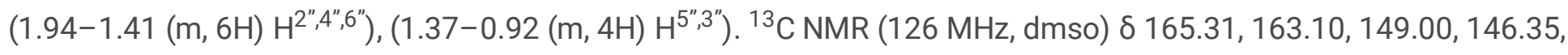
$145.47,142.77,135.12,135.05,132.86,131.48,129.66,128.29,73.08,48.56,40.49,40.32,40.16,39.99,39.82$, $39.65,39.49,32.50,32.48,25.57,24.95,24.91$. Elemental analysis calcd (\%) for $\mathrm{C}_{19} \mathrm{H}_{19} \mathrm{Cl}_{2} \mathrm{~N}_{3} \mathrm{O}_{3}(407.08): \mathrm{C}, 55.89$; $\mathrm{H}, 4.69 ; \mathrm{N}, 10.29 ;$ found: C,57.01;H,5.76;N,11.41.

\subsubsection{2-(cyclohexylamino)-2-oxo-1-(p-tolyl)ethyl pyrazine-2-carboxylate(p18)}

Yield: $48 \%$, mp: $180-182^{\circ} \mathrm{C}$, white solid. IR (KBr disk): (3275.50 ( $\mathrm{NH}$ amid group)), (3068.59-3037.58 (CH aromatic)), (2939.29-2855.41 (CH aliphatic)), (1731.89 (C= O ester)), (1656.44 (C= O amid)), (1545.71-1494.55 (C= C aromatic)), (1127.78 (C-0)) $\mathrm{cm}^{-1}$. ${ }^{1} \mathrm{H}$ NMR $\left(499 \mathrm{MHz}, \mathrm{DMSO}-d_{6}\right) \delta\left(9.28(\mathrm{~s}, 1 \mathrm{H}) \mathrm{H}^{6^{\prime}}\right),\left(8.88(\mathrm{~d}, J=35.5 \mathrm{~Hz}, 2 \mathrm{H}) \mathrm{H}^{2^{\prime} .3^{\prime}}\right)$, $(8.22(\mathrm{~d}, J=7.6 \mathrm{~Hz}, 1 \mathrm{H}) \mathrm{NH}),\left(7.34(\mathrm{dd}, J=125.5,7.3 \mathrm{~Hz}, 4 \mathrm{H}) \mathrm{H}^{6,5,2,3}\right),\left(6.08(\mathrm{~s}, 1 \mathrm{H}) \mathrm{CH}^{*}\right),\left(3.51(\mathrm{~s}, 1 \mathrm{H}) \mathrm{H}^{1 "}, 2.49(\mathrm{~s}, 3 \mathrm{H})\right.$

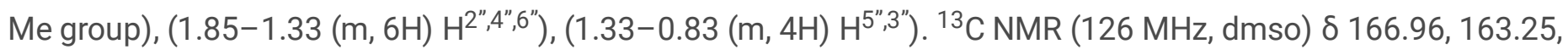
$148.79,146.24,145.42,143.18,138.55,133.05,129.46,127.85,76.68,48.20,40.33,40.16,39.99,39.83,39.66$, $39.49,32.69,32.50,25.59,24.93,24.85,21.24$. Elemental analysis calcd (\%) for $\mathrm{C}_{20} \mathrm{H}_{23} \mathrm{~N}_{3} \mathrm{O}_{3}(353.17): \mathrm{C}, 67.97$; H,6.56; N,11.89;found: C,68;H,6.59;N,11.92.

\subsubsection{2-(cyclohexylamino)-2-oxo-1-phenylethyl pyrazine-2-carboxylate(P19)}

Yield: $62 \%$, mp: $172-174^{\circ} \mathrm{C}$, white solid. IR (KBr disk): (3315.29 (NH amid group)), (3071.59-3030.32 (CH aromatic)), (2933.82-2857.39 (CH aliphatic)), (1725.84 (C= O ester)), (1665.11(C= O amid)), (1549.11-1498.04 (C = C aromatic)), (1131.69 (C-0)) cm ${ }^{-1}{ }^{1}{ }^{1} \mathrm{H}$ NMR $\left(300 \mathrm{MHz}, \mathrm{DMSO}-d_{6}\right) \delta\left(9.29(\mathrm{~s}, 1 \mathrm{H}) \mathrm{H}^{6^{\prime}}\right),\left(9.05-8.70(\mathrm{~m}, 2 \mathrm{H}) \mathrm{H}^{3^{\prime}, 2}\right)^{\prime},(8.29$ $(\mathrm{d}, J=7.8 \mathrm{~Hz}, 1 \mathrm{H}) \mathrm{NH}),\left(7.80-7.24(\mathrm{~m}, 5 \mathrm{H}) \mathrm{H}^{2,3,4,5,6}\right),\left(6.09(\mathrm{~d}, J=18.1 \mathrm{~Hz}, 1 \mathrm{H}) \mathrm{CH}^{\star}\right),\left(3.50(\mathrm{~s}, 1 \mathrm{H}) \mathrm{H}^{1 ”},(1.88-1.35\right.$ $(\mathrm{m}, 6 \mathrm{H}) \mathrm{H}^{2 ", 4 " 6 " 6)}$, (1.41-0.84 (m,4 H) H H",5"). ${ }^{13} \mathrm{C}$ NMR (75 MHz, DMSO) $\delta 166.78,166.38,162.77,148.37,145.82$, 144.96, 142.64, 135.51, 128.67, 128.46, 127.37, 76.24, 47.73, 40.32, 40.04, 39.76, 39.48, 39.20, 38.93, 38.65, 32.21, 32.01, 25.09, 24.43.. Elemental analysis calcd (\%) for $\mathrm{C}_{19} \mathrm{H}_{21} \mathrm{~N}_{3} \mathrm{O}_{3}(339.16): \mathrm{C}, 67.24 ; \mathrm{H}, 6.24 ; \mathrm{N}, 12.38$;found:

$\mathrm{C}, 67.28 ; \mathrm{H}, 6.28 ; \mathrm{N}, 12.42$.

\subsubsection{1-(3-bromophenyl)-2-(cyclohexylamino)-2-oxoethyl pyrazine-2-carboxylate(P20)}

Yield: $68 \%$, mp: $142-145^{\circ} \mathrm{C}$, white solid. IR (KBr disk): (3224.06 (NH amid group)), (3080.35-3025.97 (CH aromatic)), (2933.07-2854.21 (CH aliphatic)), (1739.68(C = O ester)), (1650.87(C= O amid)), (1571.77-1413.39 (C = C aromatic)), (1164.44 (C-0)), (754.90 (C-Br)) cm ${ }^{-1} .{ }^{1} \mathrm{H}$ NMR (300 MHz, DMSO-d6) $\delta\left(9.30(\mathrm{~s}, 1 \mathrm{H}) \mathrm{H}^{6}\right),(8.89(\mathrm{~d}, \mathrm{~J}=20.3 \mathrm{~Hz}, 2 \mathrm{H})$ $\left.\mathrm{H}^{2^{\prime}, 3^{\prime}}\right),(8.36(\mathrm{~d}, J=7.4 \mathrm{~Hz}, 1 \mathrm{H}) \mathrm{NH}),\left(8.01-7.17(\mathrm{~m}, 4 \mathrm{H}) \mathrm{H}^{2,4,5,6}\right),\left(6.09(\mathrm{~d}, J=18.5 \mathrm{~Hz}, 1 \mathrm{H}) \mathrm{CH}^{\star}\right),\left(3.50(\mathrm{~s}, 1 \mathrm{H}) \mathrm{H}^{1 \prime}\right)$,

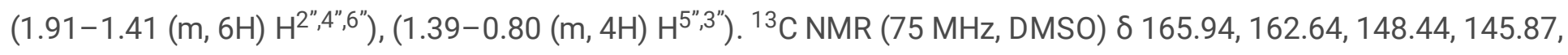
144.97, 142.49, 138.03, 131.58, 130.75, 130.03, 129.90, 126.34, 121.56, 75.39, 47.79, 40.32, 40.04, 39.76, 39.48, 39.21 , 38.93, 38.65, 31.97, 25.07, 24.39. Elemental analysis calcd (\%) for $\mathrm{C}_{19} \mathrm{H}_{21} \mathrm{BrN}_{3} \mathrm{O}_{3}(417.07): \mathrm{C}, 54.56 ; \mathrm{H}, 4.82$; $\mathrm{N}, 10.05$; found: $\mathrm{C}, 54.49 ; \mathrm{H}, 4.75 ; \mathrm{N}, 9.98$.

\subsection{MTT assay}

The synthesis compounds were tested for cytotoxic activity on cancer cell viability by MTT (3 (4,5 dimethylthiazol2yl) 2,5diphenyltetrazolium bromide) against human colon adenocarcinoma cell line (HT-29), lung cancer epithelial cell line (A549), breast adenocarcinoma (MCF7), and human normal lung cell lines (MRC5) which were acquired from the National Cell Bank of Iran (NCBI, Pasteur Institute, Tehran, Iran). Firstly, the cells were seeded 
in 96-well microplates with a density of $0.8 \times 10^{4}$ cells per well and kept for $24 \mathrm{~h}$ to recover. The cells were then treated in a triplicate manner with compounds (P1-P20) at varying concentrations ranging from 1 to $100 \mu \mathrm{M}$ and incubated in a humidified $\mathrm{CO}_{2}$ incubator for at least 72 hours at $37^{\circ} \mathrm{C}$. The media was discarded entirely after incubation and replaced with $150 \mu$ l of RPMI 1640 containing $0.5 \mathrm{mg} / \mathrm{mL}$ MTT solution and incubated for $3 \mathrm{~h}$ at room temperature. The media containing MTT was discarded again to dissolve the formazan crystals, and $150 \mu$ of DMSO was applied to each well and incubated in the dark for at least $30 \mathrm{~min}$ at $37^{\circ} \mathrm{C}$. The absorbance of the individual well was then read by ELISA reader at $490 \mathrm{~nm}$. CurveExpert 1.4 was used to measure the $50 \%$ inhibitory concentration of each compound, reflecting $\mathrm{IC}_{50}$. The data are given as mean $\pm \mathrm{SD}$.

\subsection{Apoptosis assay}

The apoptotic activity of compounds P5, and P16 was further investigated utilizing the eBioscience TM Annexin V apoptosis detection kit and AnnexinV/PI labeling (Invitrogen) [22]. The A549 cell lines are pre-cultured for 16 hours before being exposed to compounds over the next 24 hours. In sum, $0.5 \times 10^{5}$ cells per $1 \mathrm{ml}$ of complete culture medium were seeded in a 24-well culture plate, treated with P5, and p16 compounds in different concentrations (7, and $14 \mu \mathrm{M})$, and $(3,6 \mu \mathrm{M})$ respectively for $24 \mathrm{~h}$. Cells were washed once with phosphate buffered saline (PBS), and once with $1000 \mu \mathrm{L} 1 \mathrm{X}$ binding buffer. In the next step, the cells were suspended with $100 \mu \mathrm{L}$ of binding buffer containing $5 \mu \mathrm{L}$ of Annexin V-fluorescein isothiocyanate for 15 minutes. Afterward, cells were rewashed with 1000 $\mu \mathrm{L}$ Binding buffer and resuspended in $200 \mu \mathrm{L}$ of the same buffer containing $5 \mu \mathrm{L}$ of Propodium lodide (PI) solution. The apoptosis rates were then determined by BD FACS CaliburTM flow cytometry (BD Biosciences, San Jose, CA, USA). This assay can show apoptosis rates were calculated as the sum of early apoptosis and late apoptosis.

\subsection{Gel electrophoresis}

Gel electrophoresis analysis was performed using 500 ng plasmid, pBlu2KSM, DNA in 10 mM Tris-HCl buffer, pH 7.4 with the final concentrations of $20-150 \mu \mathrm{M}$ complex in a total volume of $10 \mu$. The samples were then incubated

for $60 \mathrm{~min}$ at $37^{\circ} \mathrm{C}$, followed by electrophoresis on $1 \%$ agarose gel in TAE buffer containing $1.0 \mu \mathrm{g} \mathrm{ml}{ }^{-1}$ safe stain at $100 \mathrm{~V}$ for 30 min and finally, photographed under UV light. To investigate the DNA-ligand ability of each compound to unwind the supercoiled conformation of pBlu2KSM was determined by electrophoretic mobility on the native plasmid. As expected, three different pBlu2KSM conformations were observed on the agarose gels. These were the negative open circular form (NSC) as well as single break nicked supercoil (SSNSC) and a strong bond of the positive twisted supercoiled (PSC) [23]. The Double-strand break of the circular supercoil transform circular DNA to Linear (L) format with natural length of the plasmid is shown as these conformations resolve on agarose gels as distinct bands, as shown in Fig. 2.

\subsection{Molecular docking}

The molecular docking study of the synthesis compounds was carried out using conventional methodology and techniques, as detailed in the report [24]. The crystal arrangements of three-dimensional crystals Bcl-2 (PDB ID: 6qgk), and DNA (PDB ID: 1LEX) is downloaded from the protein data bank (www.rcsb.org/pdb). The protein was prepared by removing water molecules and ligands that were not implicated in the active site and co-crystal ligands (1-[2-] [(3S) -3-(aminomethyl)-3,4-dihydro-1H-isoquinolin-2-yl] carbonyl] phenyl] -N, N-dibutyl-5-methyl-pyrazole3carboxamide, and monoimidazole lexitropsin for $\mathrm{Bcl}-2$, and DNA respectively) were separated from their 3D crystal structures. Following that, using MGLTOOLS 1.5.6, the receptors were converted to PDBQT. The original synthesized structure was drawn using ChemBioDraw (version 12.0). Each compound was optimized using molecular mechanics (MM+) and then a quantum-based semiempirical approach for the minimization (AM1) by Hyperchem (Version 8, Hypercube Inc., Gainesville, FL, USA) software. Following that, MGLtools was used to convert the output 
results of optimized structures to PDBQT. Then, using an AutoDock 4.2 batch script (DOCKFACE) based on the Lamarckian evolutionary process, docking was done on flexible molecules and rigid receptors. The grid box was determined by the dimensions of $(32,30$, and 28$)$ with center grid of $(1.861,0.439,19.153)$, and $(40,40$, and 46$)$ with center grid of $(10.227,20.84,9.478) \AA$ for the co-crystal ligand in bcl-2, and DNA respectively. The Autodock tools application (ADT, Version1.5.6) and PLIP (fully automated protein-ligand interaction profiler) were used to examine the binding interactions between docked potent drugs and their targets. The lowest binding energy conformation was chosen as the best binding mode for the AutoDock scoring system.

\section{Declarations}

\section{ETHICAL APPROVAL AND CONSENT TO PARTICIPATE}

IR.AJUMS.REC.1399.051

\section{CONFLICT OF INTEREST}

The authors declare no conflict of interest, financial or otherwise.

\section{ACKNOWLEDGEMENTS}

The authors would like to thank research deputy Ahvaz Jundishapur University of Medical Sciences who support this work. Collaboration of Toxicology Research Center and Medicinal Chemistry department, school of pharmacy, Ahvaz Jundishapur University of Medical Sciences, in providing the required facilities for this work is greatly acknowledged. This article was extracted from thesis by Shiva Akhlaghi (Grant No: TRC-9902, Ethics: IR.AJUMS.REC.1399.051).

\section{References}

1. Sung H, Ferlay J, Siegel RL, Laversanne M, Soerjomataram I, Jemal A et al (2021) Global cancer statistics 2020 : GLOBOCAN estimates of incidence and mortality worldwide for 36 cancers in 185 countries. Cancer J Clin 71(3):209-249

2. Anam F, Abbas A, Lo KM, Hameed S, Naseer MM (2014) Homologous 1, 3, 5-triarylpyrazolines: synthesis, CH... $\pi$ interactions guided self-assembly and effect of alkyloxy chain length on DNA binding properties. New $\mathrm{J}$ Chem 38(11):5617-5625

3. Rana M, Arif R, Khan Fl, Maurya V, Singh R, Faizan Ml et al (2021) Pyrazoline analogs as potential anticancer agents and their apoptosis, molecular docking, MD simulation, DNA binding and antioxidant studies. Bioorg Chem 108:104665

4. Thakor KP, Lunagariya MV, Bhatt BS, Patel MN (2018) Synthesis, characterization and biological applications of some substituted pyrazoline based palladium (II) compounds. Appl Organomet Chem 32(11):e4523

5. Pistritto G, Trisciuoglio D, Ceci C, Garufi A, D'Orazi G (2016) Apoptosis as anticancer mechanism: function and dysfunction of its modulators and targeted therapeutic strategies. Aging 8(4):603

6. Abulkhair HS, Turky A, Ghiaty A, Ahmed HE, Bayoumi AH (2020) Novel triazolophthalazine-hydrazone hybrids as potential PCAF inhibitors: Design, synthesis, in vitro anticancer evaluation, apoptosis, and molecular docking studies. Bioorg Chem 100:103899 
7. Fulda S, Debatin K-M (2006) Extrinsic versus intrinsic apoptosis pathways in anticancer chemotherapy. Oncogene 25(34):4798-4811

8. Mermer A, Keles T, Sirin Y. Recent Studies of Nitrogen Containing Heterocyclic Compounds as Novel Antiviral Agents: A Review. Bioorganic Chemistry. 2021:105076

9. Gangarapu NR, Reddy EK, Sajith AM, Yellappa S, Chandrasekhar KB (2017) NMI/MsCl-Mediated Amide Bond Formation of Aminopyrazines and Aryl/Heteroaryl Carboxylic Acids: Synthesis of Biologically Relevant Pyrazine Carboxamides. ChemistrySelect 2(25):7706-7710

10. Revill P, Serradell N, Bolos J, Rosa E. Telaprevir (2007) Drugs of the Future 32(9):788-798

11. Schechter LE, Lin Q, Smith DL, Zhang G, Shan Q, Platt B et al (2008) Neuropharmacological profile of novel and selective 5-HT 6 receptor agonists: WAY-181187 and WAY-208466. Neuropsychopharmacology 33(6):13231335

12. Trump DL, Payne H, Miller K, de Bono JS, Stephenson J III, Burris HA III et al (2011) Preliminary study of the specific endothelin a receptor antagonist zibotentan in combination with docetaxel in patients with metastatic castration-resistant prostate cancer. Prostate 71(12):1264-1275

13. Khani-Meinagh H, Mostafavi H, Reiling N, Mahdavi M, Zarrini G (2019) Design, synthesis and evaluation of biological activities of some novel anti-TB agents with bio-reducible functional group. Biolmpacts: BI 9(4):199

14. Walker JA, Liu W, Wise DS, Drach JC, Townsend LB (1998) Synthesis and antiviral evaluation of certain novel pyrazinoic acid C-nucleosides. Journal of medicinal chemistry 41(8):1236-1241

15. Sahdev AK, Raj V, Singh AK, Rai A, Keshari AK, De A et al (2017) Ameliorative effects of pyrazinoic acid against oxidative and metabolic stress manifested in rats with dimethylhydrazine induced colonic carcinoma. Cancer Biol Ther 18(5):304-313

16. Chen D, Frezza M, Schmitt S, Kanwar J, Dou P (2011) Q. Bortezomib as the first proteasome inhibitor anticancer drug: current status and future perspectives. Curr Cancer Drug Targets 11(3):239-253

17. Rotstein BH, Zaretsky S, Rai V, Yudin AK (2014) Small heterocycles in multicomponent reactions. Chemical reviews 114(16):8323-8359

18. Gajera SB, Mehta JV, Patel MN (2015) DNA interaction, cytotoxicity, antibacterial and antituberculosis activity of oxovanadium (IV) complexes derived from fluoroquinolones and 4-hydroxy-5-((4-hydroxyphenyl) diazenyl) thiazole-2 (3 h)-thione. RSC Advances 5(28):21710-21719

19. Lim SD, Sun C, Lambeth JD, Marshall F, Amin M, Chung L et al (2005) Increased Nox1 and hydrogen peroxide in prostate cancer. Prostate 62(2):200-207. doi:10.1002/pros.20137

20. Saha B, Islam MM, Paul S, Samanta S, Ray S, Santra CR et al (2010) DNA binding ability and hydrogen peroxide induced nuclease activity of a novel $\mathrm{Cu}$ (II) complex with malonate as the primary ligand and protonated 2amino-4-picoline as the counterion. J Phys Chem B 114(17):5851-5861. doi:10.1021/jp909127a

21. Juhás M, Zitko J (2020) Molecular interactions of pyrazine-based compounds to proteins. Journal of medicinal chemistry 63(17):8901-8916

22. Möltgen S, Piumatti E, Massafra GM, Metzger S, Jaehde U, Kalayda GV (2020) Cisplatin Protein Binding Partners and Their Relevance for Platinum Drug Sensitivity. Cells 9(6):1322. doi:10.3390/cells9061322

23. Kellett A, Molphy Z, Slator C, McKee V, Farrell NP (2019) Molecular methods for assessment of non-covalent metallodrug-DNA interactions. Chem Soc Rev 48(4):971-988. doi:10.1039/C8CS00157J

24. Morris GM, Huey R, Olson AJ (2008) Using autodock for ligand-receptor docking. Current protocols in bioinformatics 24(1):8 14. 1-8.. 40 

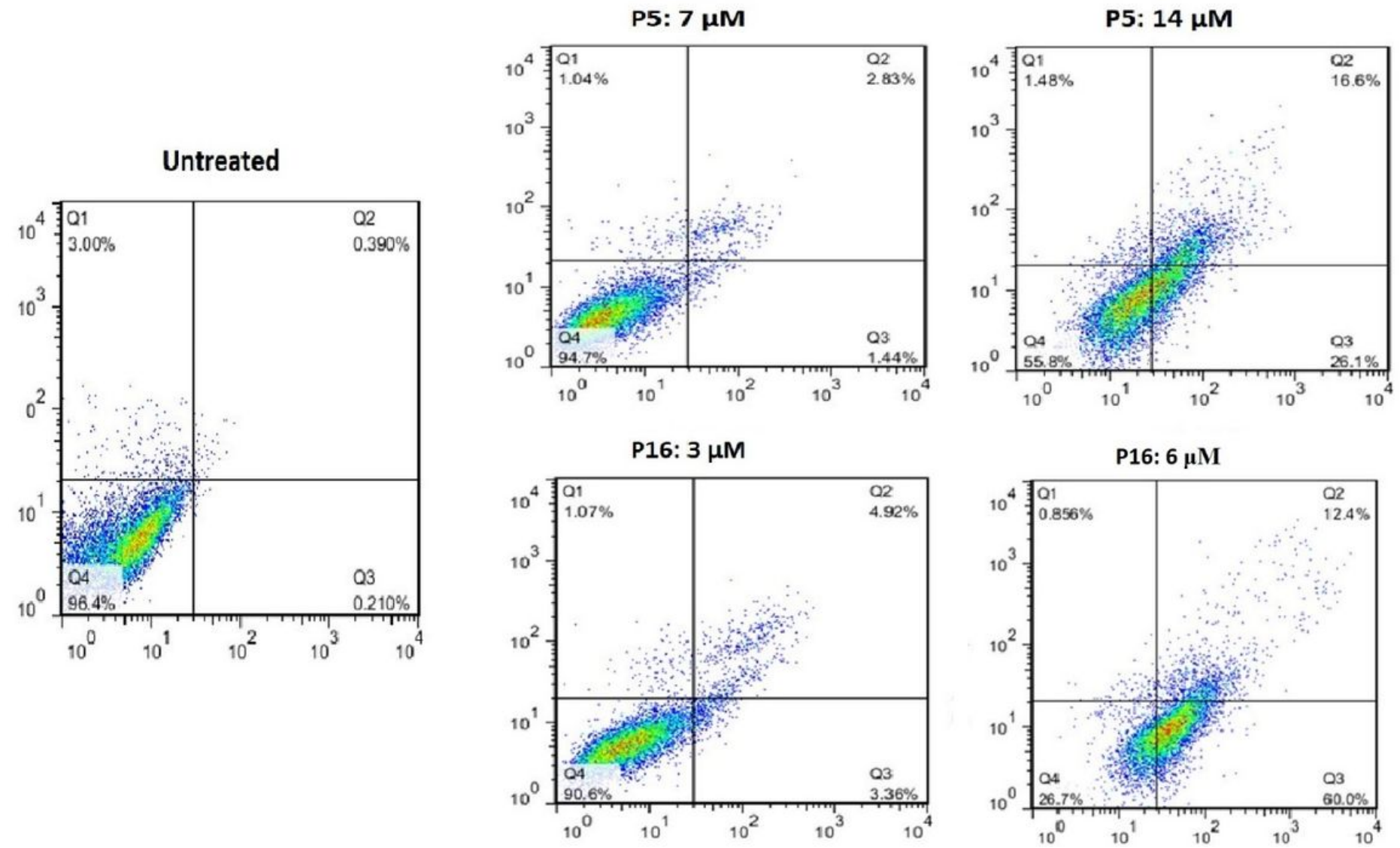

Figure 1

Flow cytometry-based detection of the apoptotic properties of P5, and P16 on the A549 cell line after $24 \mathrm{~h}$ of incubation with different concentrations of P5 (7 and $14 \mu \mathrm{M})$, and P16 (3 and $6 \mu \mathrm{M})$ using the Annexin V-PE/7AAD detection kit. The percentages of apoptotic cells (Q2: late apoptotic and Q3: early apoptotic) were determined in Annexin V + cells. Q1: necrotic cells, Q2: late apoptotic cells, Q3: early apoptotic cells, and Q4: living cells. 

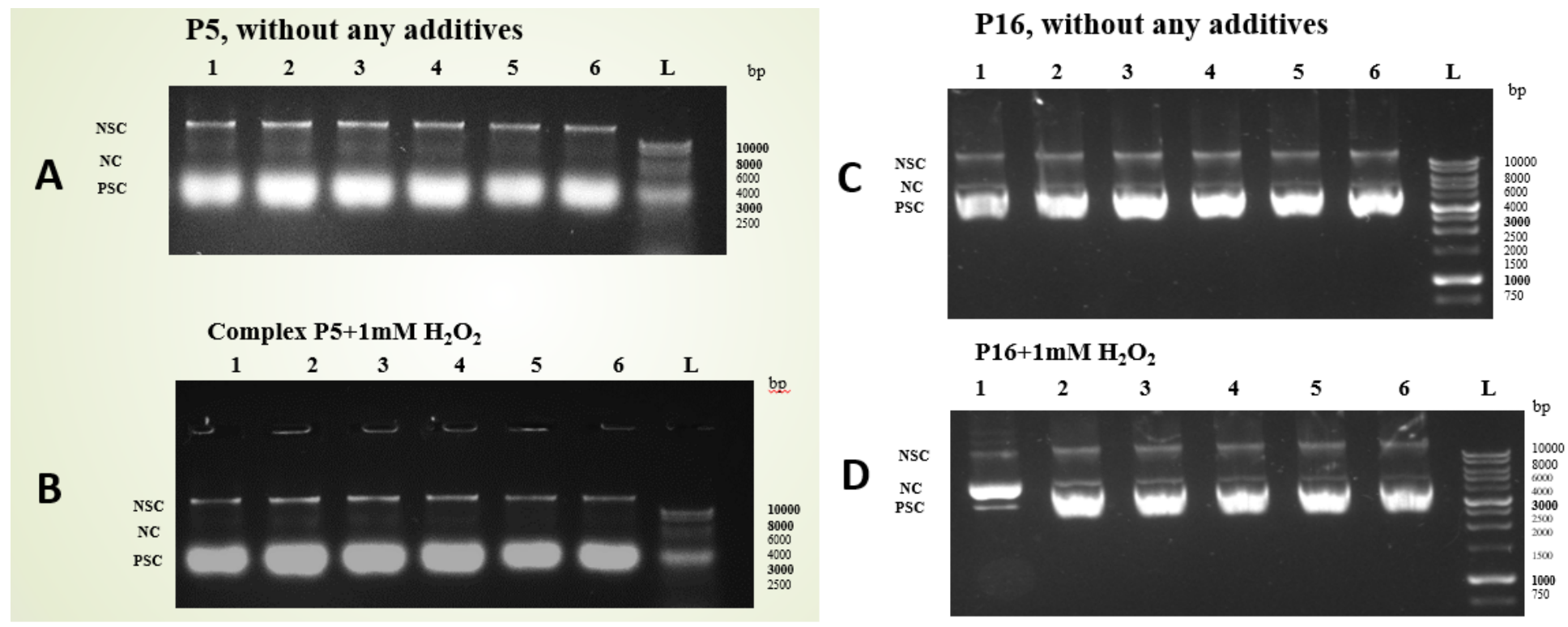

Figure 2

Electrophoresis Mobility shift assay of P5, and P16. A, C) Gel electrophoresis diagram of pBlu2KSM DNA in the presence of increasing amounts of P5, and P16. Lane 1, DNA + $150 \mu \mathrm{M}$ ligand; lane 2, DNA + $100 \mu \mathrm{M}$ ligand; lane 3, DNA + $80 \mu \mathrm{M}$ ligand; lane 4, DNA + $60 \mu \mathrm{M}$ ligand; lane 5, DNA + $40 \mu \mathrm{M}$ ligand; Lane 6, DNA (control); L; 1kb DNA ladder. Nicked circular (NC) and positive (PSC), Linear (L) and negative supercoiled (NSC) of DNA are labeled, respectively. B, D) Gel electrophoresis diagram of pBlu2KSM DNA in the presence of increasing amounts of P5, and P16 and 1mM H2O2 (lanes 1-7). Lane 1, DNA + 1mM H2O2 +150 $\mu \mathrm{M}$ ligand; lane 2, DNA + 1mM H2O2 + $100 \mu \mathrm{M}$ ligand; lane 3, DNA + 1mM H2O2 + $80 \mu \mathrm{M}$ ligand; lane 4, DNA + 1mM H2O2 + $60 \mu \mathrm{M}$ ligand; lane 5, DNA + 1mM $\mathrm{H} 2 \mathrm{O} 2+40$ MM ligand; lane 6, DNA +1 mM H2O2 (control); L; $1 \mathrm{~kb}$ DNA ladder. Nicked circular (NC) and positive (PSC), Linear (L) and negative supercoiled (NSC) of DNA are labeled, respectively. 


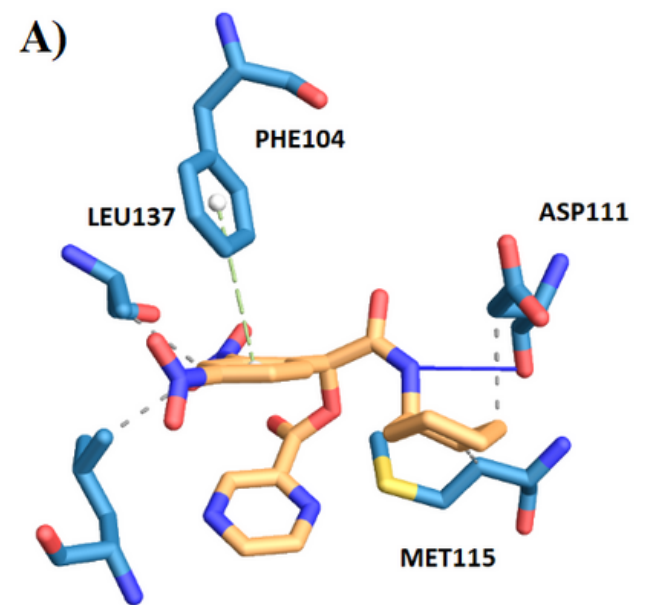

ALA149

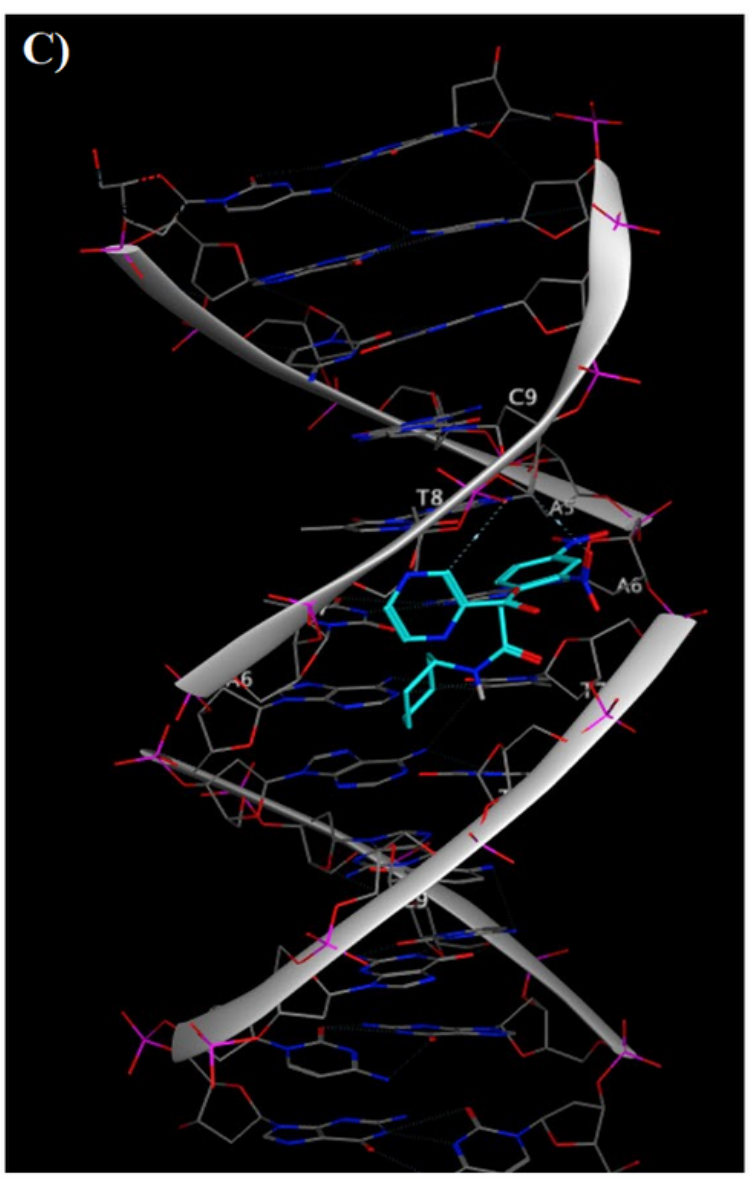

B)

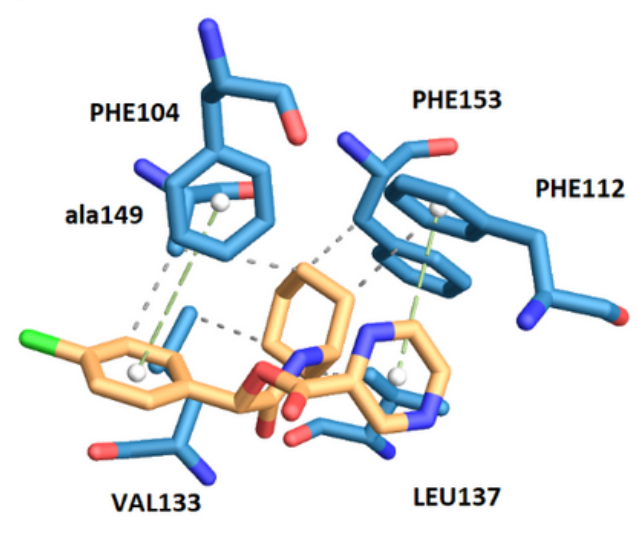

D)

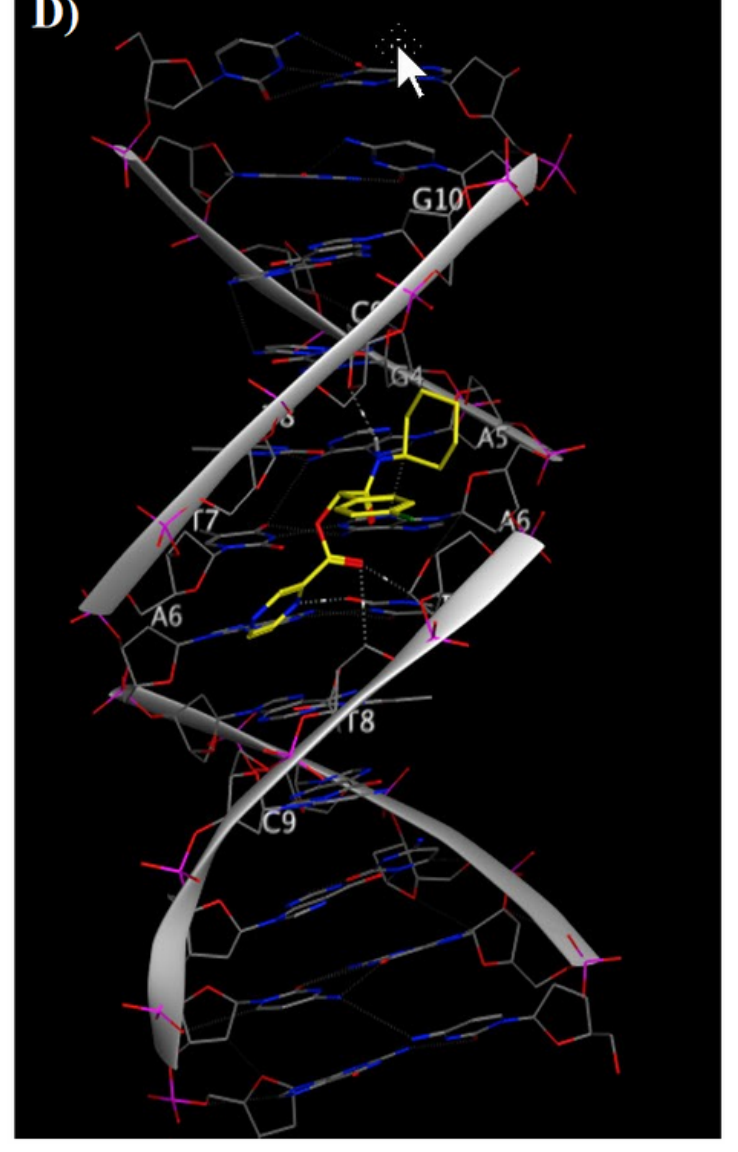

\section{Figure 3}

Interactions of P10 (A) and P16(B) with the residues in the binding site of Bcl-2 receptor. Binding mode of P10 (C) and P16 (D) in the minor groove of DNA receptor (1LEX). 

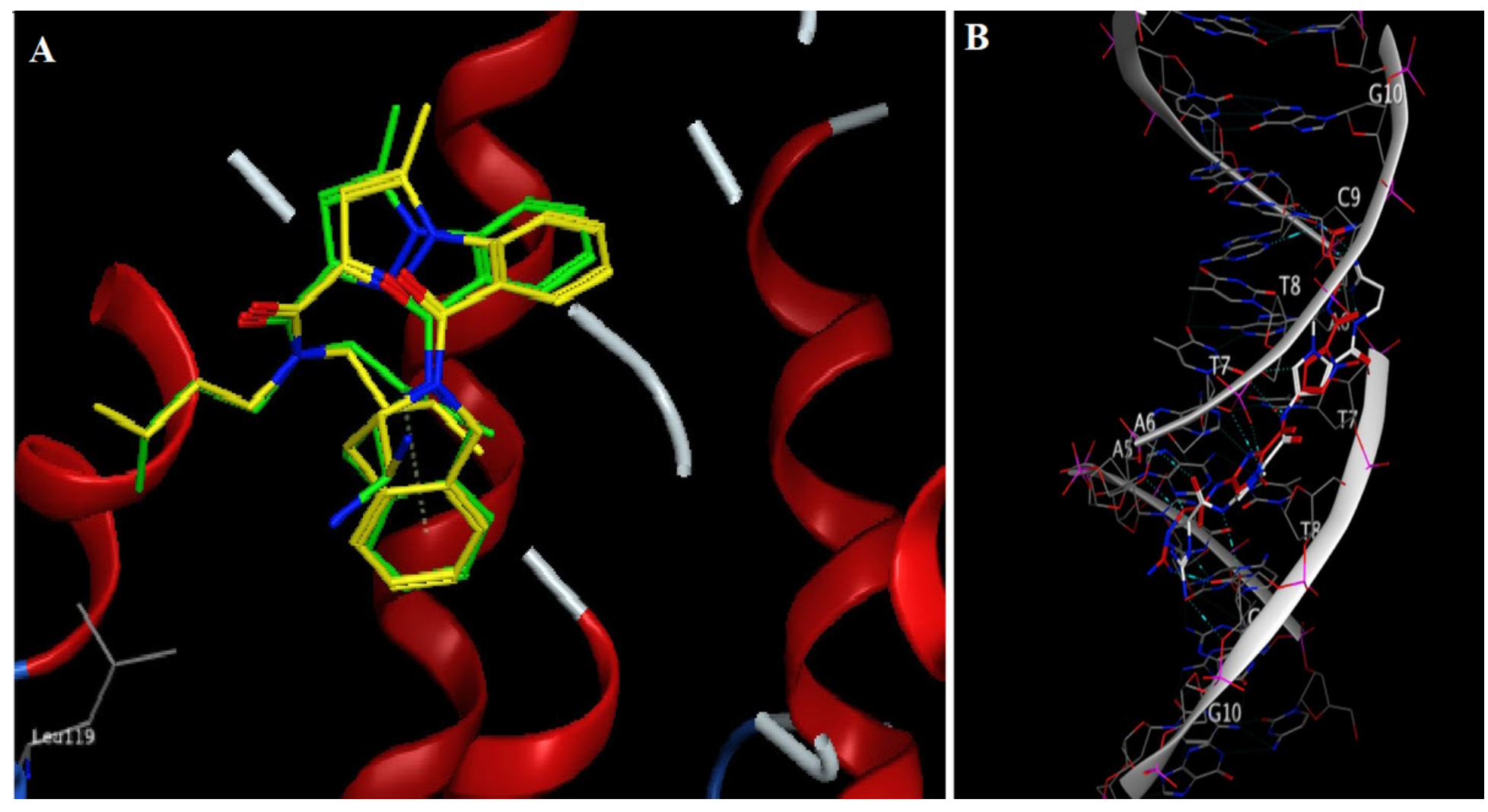

\section{Figure 4}

Re-docking of the co-crystal ligand of A) $6 q g k$, and B) 1lex indicated that the X-ray crystallography conformer (the yellow, and red for Bcl-2 and DNA, respectively) was extremely identical to the docked conformer.

\section{Supplementary Files}

This is a list of supplementary files associated with this preprint. Click to download.

- Supplementary.docx

- Onlinefloatimage1.png 